\title{
On Developments in the Mean Joint Lifetimes of Three- and Four-Generation Families in Western and Eastern Germany - A model Calculation
}

\author{
Evelyn Grünheid, Manfred G. Scharein
}

\begin{abstract}
This article tackles the question of how, on the one hand, the high life expectancy and, on the other, the increasing age of mothers at childbirth will impact the joint lifetime of three and four generations and will develop in future. To this end, indicators are derived from the official data on mortality and fertility for the mean joint lifetimes of three- and four-generation families. Because of the complicated data available, the investigation will be restricted to the female succession of generations, and here to an observation of the first-born child in each case. The indicators act as model calculations, which is why they serve above all to indicate (future) developments in mean joint lifetimes. The indicators are calculated for the average jointly-spent lifetime of three-generation families for the period from 1990 to 2060, and of four-generation families for the period from 2010 to 2060. The result of the calculations for Western Germany show an increase in the jointly-spent lifetime of three generations of up to roughly 35 years in 2000, after which that the figure falls continually to a value of roughly 30 years. A similarly developing trend emerges for four generations, but this is delayed by roughly 30 years towards the future, and reaches the highest value around 2030 to 2040, at roughly seven to ten years. For Eastern Germany, with its even younger age of women at childbirth in both the past and in the present, the maximum jointly-spent life years of three generations at the beginning of the observation period (roughly around 1990) is almost 40 years, after which this indicator falls continuously. The indicator of the average jointly-spent years of four-generation families, by contrast, probably reaches a maximum around 2020 , with a value of 12 to 14 years. Also after this, one may anticipate a reduction in the joint lifetimes of four-generation families in Eastern Germany. All in all, the trends of the indicators denote that one may not necessarily conclude from the longer life expectancy that the generations will have a longer joint lifetime, nor that the number of four-generation families will increase. Rather, the three-generation family also appears to remain the decisive generational composition of families in this century.
\end{abstract}

Keywords: Generation interval · Composition of generations in family structure · Multigenerational family $\cdot$ Model calculation 


\section{Introduction}

The view is becoming increasingly prevalent in academic discussions and in publications that, in a "society of longevity", families with four generations are increasing in number and that they will define the picture of the future. Here, the continuous increase in residual life - in particular in the higher age cohorts who have typified mortality since the middle of the last century - above all leads one to presume that the four-generation family will become the norm. Having said that, in light of such considerations there are also tendencies in the opposite direction which need to be considered. The age of mothers at the birth of their children has been increasing since the mid-seventies. One may hence anticipate that the (future) age at which mothers become grandmothers, and grandmothers in their turn become great grandmothers, will also increase. If this increase, which accumulates over several generations, is however faster than that of residual life, the mean joint lifetime of the four generations is likely to fall. If, for instance, the generation interval (which is estimated with the average age at which women have children) increases to 35 , mothers would become grandmothers at an average age of 70 and grandmothers would have to become 105 in order to see their great grandchildren. In the final analysis, however, this conceptual game generates the research question to be addressed in this article: Is it possible to measure or estimate the mean joint lifetimes of successions of generations of family compositions on the basis of the official mortality and fertility data? The authors' main hypothesis here consists of the presumption that the increasing age of mothers at childbirth, and hence also the rising age at which mothers become grandmothers, and at which the latter in turn become great grandmothers, will be more likely to lead to a reduction than to an increase in the joint lifetimes of three or four generations in the coming decades.

To answer this research question, this article will use model calculations to reveal the trends on which the development of the joint lifetime of the generations is based. The model calculations are founded on a whole series of assumptions, some of which tend to be reasoned more by plausibility considerations than by strict formal and academic criteria. The results obtained in this article therefore take account of the imprecisions which of necessity come about in that they do not speak of an estimation or forecast of the mean joint lifetime of three or four-generation families, but of indicators (and their projection) for this mean joint lifetime.

The idea as to how to construct such indicators also emerges from the above exemplary consideration. If one knows at a fictive point in time of the birth of a child, related to a whole, the average age of the mothers, grandmothers and great grandmothers (and hence also their average birth cohorts), it is possible to read from a suitable, selected cohort life table the average expected residual lifetime of the (fictive) child with his/her "average mother", "average grandmother" and "average great grandmother". These values can be interpreted as a mean joint lifetime of the various successions of generations "mother/child", "grandmother/child" and "great grandmother/child". Because of the data available, it is necessary, finally, to restrict the calculations to modelling the female succession of generations. This is however of secondary significance to answer the research question, given that, according to 
current research knowledge, the generation intervals for the male generations are longer than those of women since men are on average older than women at the birth of their children. Hence, analogously to the above considerations, the mean joint lifetime of men with their children, grandchildren and great grandchildren is much shorter than that of women. For this reason, the restriction to the female succession of generations - and they are related in each case to the first child - ultimately leads to a certain amount of estimation of the maximum mean joint lifetime of three- and four-generation families. The results for the mean joint lifetime of mother and child are not presented in this paper since they are of secondary relevance for the enrichment of the academic discussion of the question of whether the family associations will be more likely to consist of three or four generations.

Firstly, in addition to defining terms, section two of this paper outlines the historical and current state of research on the development of three- and four-generation families. Since no one was dealing with the topic until about the mid-1980s, the listed literature does not distinguish between Western and Eastern Germany. This differentiated approach is not followed until the calculations because the different age of women at childbirth in the past and also in the present leads one to anticipate different developments in the future here. The third section serves to formally elucidate the manner in which the indicators and their future extrapolations are ascertained, as well as to describe the data used. Since the calculations act as model calculations, the results for the mean joint lifetimes of three- and fourgeneration families in the three main scenarios are presented in section four. In the following fifth section, an investigation is carried out with a sensitivity analysis as to the direction and sensitivity at which the indicators react to changes in the assumptions. Finally, the overall calculations will show above all that the development of the average age of a mother at the birth of her (first) child is the decisive influencing factor for the future course of the mean joint lifetimes of three- and four-generation families over the next 60 years, rather than an increase in mean residual life. If the average age of mothers at the birth of their children also increases in the future, the mean joint lifetime both of three- and four-generation families will decrease in future. This circumstance will also mean that the shares of four-generation families in Germany will tend to fall in future. Section six concludes by summing up the overall the results of this paper.

\section{State of research}

It was only in about the mid-1980s that a growing academic interest in multi-generational relationships became recognisable in sociological circles, with transfer and support benefits, as well as contact intensity and contact quality, primarily becoming the focus of the analyses (Nave-Herz 2005: 48). Contacts, distance and proximity, as well as transfers between the generations, continue to form the focus of research into intergenerational relationships today. 


\subsection{Definitions}

The definition of "generation" taken as a basis for our research is generally viewed at two levels:

- as a societal definition of "generation", against the background of common features shared by identical or neighbouring birth cohorts in a specific historical (political, cultural and economic) environment, as well as;

- as a familial definition of "generation" or lineage: here, affiliation to a generation always remains identical, whilst the position within the succession of generations changes - children become parents and later grandparents or even great grandparents (cf. on this Szydlik/Künemund 2009: 9; Lüscher/ Liegle 2003: 59 et seq., 90).

The familial definition of "generation" is used for the topic of this article. The term "multigenerational family" is used in this paper in analogy to Lauterbach (2002: 542) "in order to distinguish a living arrangement in which at least three generations are interlinked by lineage or adoption in the succession of generations from the living arrangement constituted by the nuclear family." ${ }^{1}$

\subsection{Historical development}

The three-generation family is taken for granted today, but it is however something rather new in historical terms. Up until the 20th Century, a family model was prevalent for large sections of the population in Germany which today is summarised by the term "Western family" or "European marriage pattern", and which was typified by a high average marital age and low life expectancy. Around 1800, for instance, women in Germany married at an average age of 26, the figure for men being 28 . A relatively large proportion of people remained single all their lives. The marital age continued to rise in the 19th Century, and it was not until the final third of that century that the values fell (cf. on this Ehmer 2004: 47; Mitterauer 2009: 14, 21, 70 et seqq.; Höpflinger et al. 2006: 22-28; Eggen/Rupp 2007: 6 et seqq.). This advanced marital age was primarily due to economic factors: "Economic conditions also play a role in the characteristic European marital age. At least those groups of the population who were not able to rely on taking over an inherited household when setting up a home [for instance rural maids and servants, as well as urban messengers the author] had to have saved sufficient money for marriage to be able to make a home from scratch. [...] This led to relatively late marriages, particularly in the lower urban and rural population groups." (Mitterauer 2009: 21) Especially in these social groups, this led to a long phase of single life and late marriages. Lauterbach (2002: 541) therefore reaches the following conclusion for this period: "In historical terms, the multigenerational family is quite simply a myth. [...] Because of the low life expectancy and the high marital age, multigenerational families in the sense of several successive generations living at the same time were virtually non-existent."

$\overline{1}$ All citations from papers in German language are own translations. 
The vast majority of people who lived to an old age in the past are likely to have had children and grandchildren, but only a small number of children had surviving grandparents, and if they did, they lost them in early childhood (cf. on this Hagestad/ Herlofson 2007: 4; Farkas/Hogan 1995: 1; Uhlenberg 1996: 682; Putney/Bengtson 2003: 151 et seq.). With the fall in child and youth mortality which occurred in the First Demographic Transition, the chances increased for surviving grandparents to have a larger number of children and grandchildren. This trend halted when fertility levels underwent a massive drop at the end of the 19th Century. Especially in the second half of the 20th Century, increasing life expectancy among the elderly brings with it a new development: More and more children and juveniles have a chance to get to know their grandparents, and the joint lifespan of the three generations increases.

Taking into account the outlined historical development and calculations based on empirical data, for instance from the Socioeconomic Panel, Lauterbach and other researchers conclude that grandparenthood did not become the norm in the composition of generations in family structure until the second half of the 20th Century (Lauterbach 1994; 1995a, 1995b; 2000; 2004; Lüscher/Liegle 2003; Bengtson 2001; Höpflinger et al. 2006).

In the USA, it was above all Vern L. Bengtson (Bengtson 2001; Bengtson/ Rosentha/Burton 1990; Bengtson/Schaie/Burton 1995; Bengtson/Schütze 1992; Putney/Bengtson 2003) and Peter Uhlenberg (Uhlenberg 1995, 1996; Uhlenberg/ Kirby 1998) who dealt with recent developments in such multigenerational families; the corresponding research in Germany began above all in the context of DFG (German Research Foundation) Collaborative Research Centre 3, "Microanalytical basis of social policy", and was particularly continued in recent years by Wolfgang Lauterbach. In a joint publication with Rosenthal and Burton (1990), Bengtson indicated that changes in family structures and in intergenerational relationships are primarily caused by two demographic trends: 1. the dramatic drop in mortality since the end of the 19th Century and 2. the fall in fertility. Other influencing factors are a changed timing of births (more teenage births on the one hand and the postponement of births to a later age on the other), childlessness, growing lone child parenthood and divorces. The focus here lies on the increase in the joint lifetime of generations caused by falling mortality. The American research tends to marginalise the significance of the increasing age of mothers at birth, which is however considerable for Germany and on which this article focuses. This effect was relatively short-lived in the USA - the age of a mother at the birth of her first child increased there by roughly three years, above all between 1970 and 1990, after which only a slight increase to 25.0 was recorded up to 2006 (Mathews/Hamilton 2009: 1). A relatively large share of teenage pregnancies, combined with a low age of mothers at childbirth among Hispanics, non-Hispanic blacks, American Indians and Alaskan Natives in particular, contrasted with the increase in the age of mothers at childbirth as a whole.

Nonetheless, the family structure has undergone considerable change in the USA, which has led academic conception of "beanpole family": "One intergenerational family structure that has become increasingly common in contemporary North American society is what can be described as the 'beanpole family', the product 
of declining mortality and fertility. Also called 'verticalisation', this occurs through intergenerational extension, when the number of living generations within lineages increases, and intragenerational contraction, when there is a steady decrease in the number of members within each generation [...]. Verticalisation has many implications for the complexity and potential pool of intergenerational relationships as well as for multigeneration living arrangements." (Bengtson et al. 1990: 264)

This pattern which is typical for the USA cannot however be easily transferred to Germany. Instead, Bengtson and Schütze (1992: 500) found the following to apply to Germany: "A further intergenerational pattern emerges which is more typical for Germany than the 'beanpole'; it has been called the 'age-break structure', emerging when women do not have their first children until late in life. [...] If women postpone their first pregnancy to their mid- or even late-thirties, and in particular if this takes place over two generations or more, a family structure comes into being which has major age gaps. [...] And finally, the later in life the first child is born, the fewer children will be born altogether in all probability."

\subsection{Four-generation constellations}

The statement that in a society of longevity, four-generation families increase in number and will determine the dimensions of family life in the long term (BMFSFJ 2009) was an occasion for the authors to tackle this problem in greater detail. What is the scale of four-generation families in the family structure in Germany? Since the data available on this question are very thin, it is only possible to estimate a scale from a few empirical surveys. Table 1 provides an overview of this.

It is possible to estimate from the information contained in this table that roughly half of respondents from middle age onwards live in a three-generation family, roughly one-quarter to one-fifth live in a two-family constellation, and a maximum of one respondent in five to ten lives in a four-generation family. It is hence not possible to say anything at this point about trends because of the different survey fundamentals and respondent age cohorts. Höpflinger, Hummel and Hugentobler (2006: 27-28) found in their surveys that at the beginning of the 20th Century only $1-2 \%$ of newborn children in Switzerland had great grandparents, and stated for the present: "Only with an intergenerational tradition of starting a family early can today's children expect a longer joint life expectancy with great grandmothers and in some cases great grandfathers. If the intergenerational birth interval is 75 years, roughly two-fifths of ten-year-old children of the 1990 birth cohort can know their maternal great grandmother, and roughly one-fifth can know their paternal great grandfather; these persons already being very old, with an average age of 85 . [...] An intergenerational birth interval of 80 years in comparison to 75 already reduces the probability of a ten-year-old child having surviving great grandparents by half. If the average birth intervals between great grandchildren and great grandparents of 85 to 88 years currently actually observed in Switzerland is presumed, even lower values are shown, and children in Switzerland who can grow up with great grandparents - with its tradition of starting a family later - are clearly the exception." 
Tab. 1: Scale of the composition of generations in family structures in empirical surveys in recent years

\begin{tabular}{|c|c|c|c|c|}
\hline \multirow{2}{*}{$\begin{array}{l}\text { Databasis } \\
\text { (survey year) }\end{array}$} & \multicolumn{3}{|c|}{ No. of generations } & \multirow[b]{2}{*}{ Source } \\
\hline & Two & Three & Four & \\
\hline $\begin{array}{l}\text { Age survey (1996), } \\
40-85 \text { years }\end{array}$ & $16.0 \%$ & $55.9 \%$ & $20.1 \%$ & Hoff 2006: 245 \\
\hline $\begin{array}{l}\text { SOEP }(1996), \\
40-80 \text { years }\end{array}$ & ca. $31 \%$ & ca. $47 \%$ & ca. $9 \%$ & $\begin{array}{l}\text { Own calculations acc. to } \\
\text { Lauterbach 2004: } 107\end{array}$ \\
\hline $\begin{array}{l}\text { OASIS }(2000) \\
50-74 \text { years }\end{array}$ & $23.0 \%$ & $50.0 \%$ & $6.0 \%$ & Lowenstein/Ogg 2003: 16 \\
\hline $\begin{array}{l}\text { Age survey (2002), } \\
40-85 \text { years }\end{array}$ & $18.1 \%$ & $55.2 \%$ & $19.4 \%$ & Hoff 2006: 245 \\
\hline $\begin{array}{l}\text { SHARE }(2004) \text {, } \\
50 \text { years and older }\end{array}$ & $20.9 \%$ & $49.8 \%$ & $17.3 \%$ & Kohli et al. 2005: Annex, Tab. 4A9 \\
\hline $\begin{array}{l}\text { GGS }(2005), \\
40-79 \text { years }\end{array}$ & $24.6 \%$ & $53.5 \%$ & $9.9 \%$ & $\begin{array}{l}\text { Own calculations from the } \\
\text { Generations and Gender Survey }\end{array}$ \\
\hline
\end{tabular}

\subsection{Influencing factors on the composition of generations in family structure and the joint lifetime of the generations}

(1) As was already explained in section 2.2, the fall in mortality, and hence the increase in life expectancy, was the main reason why the cohabitation of several generations was able to become the norm at all. However, this is not the only factor influencing the length of the joint lifespan between the generations, even if the other factors receive much less attention in research and discussion.

(2) A second major influencing factor which can have both a positive and a negative impact on joint lifetimes is the age of the parents at the birth of the first children. The fall in average ages until the beginning of the nineteen seventies considerably increased the probability of three- or even four-generation constellations; the joint lifetime of the generations became longer. Since then, a continuous increase in this average age can be observed which runs counter to an extension of the joint lifetime of the generations. Depending on the level of the increase in life expectancy, an extension of this joint lifespan is nonetheless possible in the interaction of these two influencing factors. The question here is, however, what is the future development if the increasing average age adds up over several generations? This is for instance indicated by Hoff (2006: 238) with the following statement: "On the one hand, with ongoing increases in life expectancy the probability of the existence of more than three generations in the expanded family network also increases. Great grandparents and great grandchildren are no longer a rarity. On the other 
hand, the increasing age of German women at the birth of their first children leads to an increase in the interval between the generations. It is still unclear which of the two trends will have the more pronounced effect on generation constellations in the second half of life, meaning whether an increase or a decrease in the prevalence of multiple-generation constellations can be anticipated within the expanded family." (cf. on this also Höpflinger et al. 2006; Höpflinger 2008; Lüscher/Liegle 2003; Lauterbach 1995a, 2002; Bien 1994; Bengtson/Schütze 1992). Wernhart et al. (2008: 16) estimate the influence of the increasing age of a mother at first childbirth to be even stronger: "Since this effect is twofold (women themselves become mothers later and their children again have children later [grandchildren]), one may presume in the long-term view that the birth time effect will overlap the increased life expectancy, leading in turn to a fall in the joint lifetime of grandchildren and grandparents."

(3) The falling fertility can influence the composition of generations in family structure and the joint lifespan in various directions:

- The delay in the birth of the first child to a later age reduces the probability that subsequent children are also born (cf. on this Lauterbach 2002: 543). Hence, the falling number of children per woman tends to push towards a reduction in the average age of births if one views age over all children born (fewer children are born per woman and the age of the mother at the birth of the last child falls). Successive generations hence have fewer children and hence fewer and fewer grandchildren and great grandchildren (cf. e.g. Hoff 2006: 234).

- The rise in childlessness leads to the succession of generations not being continued; family generational lines break. Childless men and women hence live in intergenerational relationships which go only in one direction (towards the elderly), and which as a rule consist of a maximum of two generations. All in all, therefore, the proportion of families with three and more living generations also diminishes as childlessness increases.

(4) In addition to demographic influencing factors, social and historical conditions may also impact the joint lifespan. For instance, the joint lifetime of grandchildren and grandparents from higher social groups may be positively influenced by their longer life expectancy. Above all, historical influences are also shown in Germany in connection with the two World Wars. There are pronounced gender-specific differences here which will be briefly outlined below.

\subsection{Gender-specific differences in the joint lifetime of the generations}

The gender-specific differences in joint lifetimes are the result of several processes acting at once - the higher life expectancy of women, the impact of the two World Wars, and the different marital age between men and women, all adding up to a pronounced overhang of women in the high age cohorts. These processes result in 
fathers having a much lower probability of becoming grandfathers or great grandfathers at all, and if they did of having a shorter joint lifespan with their grandchildren or great grandchildren (cf. z.B. Lauterbach 1995a, 2000, 2004; Hoff 2006).

The higher life expectancy of women is not to be dwelled on at this stage; this finding is sufficiently known from surveys on mortality (e.g. Luy 2002). The First and Second World Wars particularly led to an above-average increase in mortality among men in the birth cohorts between 1900 and 1930, so that these men's children were frequently only able to spend a short joint time with their fathers, and the grandchildren of these cohorts had particularly few grandfathers.

The difference in the marital age of women and men is estimated to be between three and four years. The influence of this factor on the generation structure is presented by Lauterbach (2004: 79) as follows: "These age differences accumulate over two generations to such a degree that a notable age difference on the transition into the family phase of grandparenthood between the filiation lines and the genders can be found. Consequently, it would have to be added that the maternal grandmother is the youngest within this generational structure and the paternal grandfather the oldest. Independent of the wars that were waged in the first half of the 20th Century, or of other social influences, there are hence [...] structural particularities exerting a major influence on the generational structure in families."

The above makes it evident that it is not sufficient to conclude from the longer life expectancy a generally longer joint lifetime of the generations and an increase in the number of four-generation families. The daughters of the now still relatively young grandmother generations, who delayed starting a family, will increase the intergenerational age differences and will enter grandparenthood at a much later age than their mothers' generations. To what degree this development can be equalised by the increasing life expectancy is questionable. On this Wolfgang Lauterbach (2002: 543) has the following to say: "As to the differentiated development of the age of starting a family in Germany, it is found that a successive bringing forward of births in life courses took place among those born up until the mid-1940s. By contrast, the younger birth cohorts show a considerable delay in the family-starting phase [...] The heightened life expectancy and the bringing forward of starting a family initially acted together to increase the joint lifetime. The further development of the joint lifetime of parents and children is however open: No statement can yet be made as to the further (residual) life expectancy of the younger generations after starting a family. In view of the considerable delay in starting a family, however, for the future (at least among college graduates) one may presume only a slight postponement, perhaps even stagnation."

The chapters below help to gain an understanding of the considerations put forward here on the developments in the joint lifetimes of three- and four-generation families using data from official statistics and to estimate the coming trends for the years to come. 


\section{$3 \quad$ Data and modelling}

Before explaining in the next section how the indicators and their extrapolation are ascertained for the future, a brief description of the important demographic benchmarks is to introduce the topic and make it clear why separate calculations are carried out for Western and Eastern Germany. The benchmark which is most important in this context is the age of mothers at the birth of their children. This is where incisive changes have taken place in recent decades in that the age of mothers at childbirth for all children, having reached a low in the mid-nineteen seventies (FRG 26.7, GDR 24.6), increased continually to 30.2 in Western Germany and to 29.3 in Eastern Germany. Major age differences occur here if one compares out-of-wedlock births and the birth of the first children in an existing marriage, accounting for 1.7 years in the West and 2 in the East. If one considers furthermore that almost $58 \%$ of children in Eastern Germany are born out of wedlock, thus twice as many as in Western Germany, it becomes clear that demographic differentiations between the West and the East in this respect have persisted to the present day. This also relates to the proportion of childless women, who account for around $19 \%$ in Western Germany, and about $7 \%$ in Eastern Germany, in the birth cohorts around 1960 whose fertility biography is completed. Whilst this share has remained virtually unchanged in Eastern Germany in comparison to the older women's cohorts, it has increased in the West by roughly two-thirds in comparison to women in the 1930s cohorts. With regard to mortality, the differences between Western and Eastern German women have virtually vanished here; identical circumstances may be presumed for the future in this respect.

It is however not possible with data from official statistics either to ascertain the frequency of the occurrence of certain compositions of generations in family structure, or to make any concrete statements on the average generation intervals. It is possible to use survey data (e.g. age survey, SOEP, OASIS, SHARE or GGS) to ascertain the scale of composition of generations in family structures, and in some cases even in an adequate level of detail. However, these datasets also prove to be unsuited to estimate over time a trend for the shares of three- and four-generation families. By contrast, it is however possible to develop from the data of official statistics via model calculations two indicators which show the (future) course taken by levels of three- and four-generation families. The idea behind the calculation of these indicators is a measurement of the joint lifetime of successive generations. However, because of the data available in Germany, it is necessary to restrict the investigation to ascertaining the joint lifetime of great grandmothers and great grandchildren and of grandmothers and grandchildren. Only then do the data available from official statistics permit such joint lifetimes to be estimated via indicators and their course projected for the future. It must however be heavily underlined that this essay quite deliberately refrains from speaking of either measuring or estimating the joint lifetime of successive generations since all results come from model calculations. What is more, the indicators developed contain a whole series of implicit and explicit assumptions and (mathematically and technically) unsolvable imprecisions, so that the precision implied by the terms estimation or forecast is not tenable 
here. This analysis aims to say something about the historical and future development of trends in the joint lifetime of great grandmothers and great grandchildren and of grandmothers and grandchildren, and does not provide an estimated value of this joint lifetime at a certain time of the calculation. The imprecision contained in the calculations is to be made clear via the expression "indicator" for the joint lifetime. Since the calculations to be carried out are additionally purely average observations, we speak of (indicators for) mean joint lifetime. Hence, finally, one indicator shows both a trend and a curve statement on the mean joint lifetime of four generations - that is of great grandmothers and their great grandchildren. The other indicator describes analogously the course of the mean joint lifetime of three generations - that is of grandmother and their grandchild.

\subsection{The average age of a woman at the birth of the first child}

The starting point of the considerations is the view of the (almost exclusively) female succession of generations, great grandmother, grandmother, mother and grandchild. Of this succession of generations, however, only the special case is additionally observed that the first child of the great grandmother was female (here then referred to as "the grandmother") and the first child of the grandmother was also female (here then referred to as "the mother"). The gender of the mother's firstborn child is irrelevant in this observation of the mean joint lifetime, since a positive value for the mean joint lifetime implies that, on average, both generations are still alive and know one another and a negative value placed on this contrarily depicts an experience which, on average, no longer takes place. In order to ascertain such indicators, there is a need first of all to know the average age of a woman at the birth of her first child over time. These data should be available with the observation to be carried out here as a time series with considerable length, which is not revealed at all by the data of the official statistics, and certainly not over an adequate period. Since, however, the age-specific fertility rates (separated by Western and Eastern Germany) are available in the official statistics from 1956 onwards, a pragmatic approach is chosen here, and an estimator for the average age of a woman at the birth of her first child (albeit a biased one) is ascertained from these data. ${ }^{2}$ Because the average age of a woman at the birth of a child calculated on the basis of the age-spe-

2 The age-specific fertility rates for Eastern Germany for 1956 to 1989 originate from the "Sonderreihe mit Beiträgen für die ehem. DDR" (Statistisches Bundesamt 1993: 77 et seqq.), and were supplied for Western Germany by the Federal Statistical Office. For the period 1990 to 2008, the age-specific fertility rates from the age-specific information on official statistics for the number of live births and women by Western and Eastern Germany were calculated separately. The special case of Berlin was tackled by the data for Berlin from 1990 onwards being attributed neither to the East nor to the West of Germany, and hence removed from the calculations. Since the influence of the data from Berlin on the shape of the age-specific fertility rate distributions for Western and Eastern Germany tends to be slight, the resulting biased effect - which only occurs if the appearance of the age-specific fertility rate distribution of Berlin differs from that of Western or Eastern Germany - in the calculation of an estimator for the age of a mother at the birth of her first child is likely to be low, and hence negligible in the calculation of the indicators. 
Fig. 1: $\quad \alpha$-quantiles for the age of a mother at the birth of a child in Western and Eastern Germany for 1956 or rather 1951 to 2008
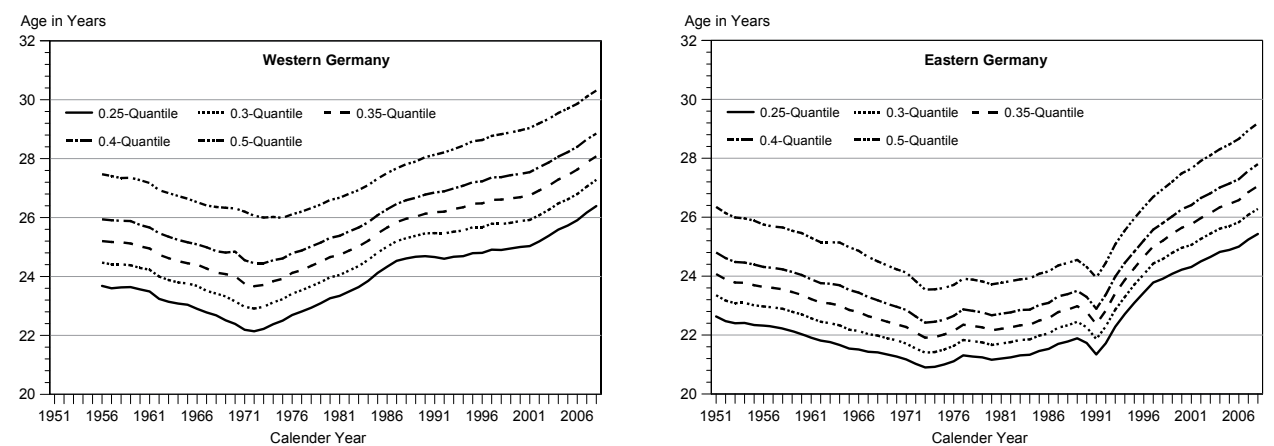

Source: Own calculations

cific fertility rates is above the age of a woman at the birth of the first child - this also applies to the corresponding median age - a suitable $\alpha$-quantile is selected here that is below the median age, that is $\alpha<0.5$, as the estimated value for the average age of a mother at the birth of her first child. ${ }^{3}$ Figure 1 shows developments in the age of a mother at birth for Western and for Eastern Germany for various a-quantiles. Since the normed fertility rate distribution over time is always unimodal and low skewed, the developments in the $\alpha$-quantile age for different $\alpha$ are virtually identical and differ almost only by a vertical shift.

A pragmatic approach has to be taken for the selection of the suitable a-quantile to estimate the age of a mother at the birth of the first child, albeit information from the official statistics can be taken as an orientation. The respective information on the average age of the mother by birth order can be reconstructed for the GDR for 1951 to 1989 using information from the living-born statistics of the GDR (from 1973 onwards), from the Yearbooks of Population Statistics of the GDR (1966-1972), from the Statistical Annuals of the GDR (1956-1965) and from documents of the Statistical Office of the former GDR. Further information is missing with the same sociodemo-

3 In formal terms, the $\alpha$-quantile is calculated on the basis of the age-specific fertility rate distribution of a year normed by division with the corresponding total fertility rate, which having been thus normed has the characteristics of a relative frequency distribution. Here, the calculation is carried out of an $\alpha$-quantile using a relative frequency procedure for a grouped characteristic (here the age of a woman which is grouped into one-year age cohorts) according to the standard procedure of descriptive statistics, which is explained for instance in Toutenburg/Heumann 2008: 52 et seqq. The selection of a value of 0.5 for $\alpha$ would correspond to the median of the corresponding relative frequency distribution, and here to an estimated value for the mean age of a woman at the birth of a child. Since the median age of a mother at the birth of her first child must be lower than this median age, an a-quantile with a (suitably selected) smaller a must be used. When calculating the indicators for the mean joint lifetime of multigenerational families, a value for $\alpha$ of 0.35 is used in the context of the main variants. This is to be interpreted such that the average age of a mother at the birth of her first child roughly corresponds to the age by which $35 \%$ of all (age-standardised and normed) births have taken place. 
graphic characteristics from the time of reunification onwards. Only information separated by Eastern and Western Germany is then available for the average age of mothers at the birth of their first living-born child within wedlock. If, however, one observes the differences between mothers at the live birth of a child as to their legitimacy, which is available via the official statistics for 1991 to 2000 and differentiated by Eastern and Western Germany, one may deduce that mothers are much younger on average in out-of-wedlock living arrangements at the birth of a child (cf. also Fig. 2). Ultimately, as an estimated value for the age of a mother at the birth of the first child the 0.35 -quantile of the normed fertility rate distribution is regionally differentiated and used for Eastern and Western Germany. Nonetheless, the selection of the 0.35 -quantile was carried out to some degree by rule of thumb since a more expedient procedure for adapting the data based on statistical procedures is not available because of a lack of values and due to inconsistencies with regard to content and form. The considerations which lead to the selection of the 0.35 -quantile are explained briefly below:

1. For reasons of plausibility, the resulting estimated values for Western Germany should be lower than the age of a mother at the birth of a child from non-marital forms of relationship (of the mother), as well as below the age of a mother at the birth of her first child in the context of a marital living arrangement (of the mother). According to information from the Federal Statistical Office, for instance, the average age of a married mother at birth in 2008, at 31.3 , is three years higher than that of unmarried mothers. Furthermore, a married woman is on average 1.2 years younger at the birth of her first child of this marriage than at the birth of a child in general (if one therefore neglects the birth order).

2. For Eastern Germany the estimated value for the 1956 to 1989 period should roughly correspond to the average age of a mother at the birth of her first child.

Figure 2, which shows official data which are available for Western and Eastern Germany on the age of a mother at the birth of children born in and out of wedlock, as well as of the first-born children in the respective marriage, supports the selection that has been made of the 0.35 -quantile as an estimated value for the average age of a mother at the birth of the first child. It is shown in Chapter Five in the context of a 
Fig. 2: $\quad 0.35$-quantile and average age of a mother at the birth of a child in Western and Eastern Germany for the 1956 to 2008 period for children born in and out of wedlock and first-born children born in wedlock
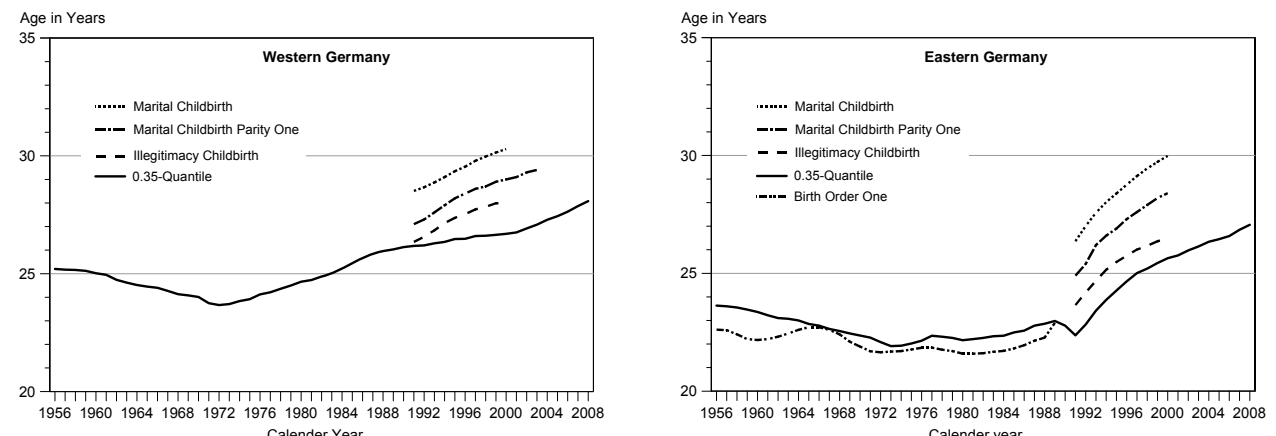

Source: Federal Statistical Office; own calculations

sensitivity analysis that the selection of another a-quantile (which is however stable over time) largely shifts the trends of the indicators only in the absolute level. ${ }^{4}$

\subsection{Future development of the average age of a mother at the birth of the first child}

Since the age-specific fertility rates for Germany are only available and useable from 1956 to 2008, the envisioned grandmother/grandchild relationships can only be presented for a short period on this databasis. The databasis is too short in the time axis to calculate the mean joint lifetime of great grandmother/great grandchild relationships. For this reason, the data are extrapolated for the future via a suitable adaptation model, and hence extended. To this end, for the time series of the ( $\alpha$-quantile) age of the mother at the birth of a child - in formal terms the values of this time series for a pre-defined $\alpha$ and at a certain time $t$ are designated below with $x_{\alpha}(t)-a$ generalised logistic function is adjusted, whereby for instance a functional

4 Since for Eastern Germany the course of the 0.35 -quantile as an estimated value for the average age of a mother at the birth of the first child from 1956 to 1989 is higher than the age of married women at the birth of their first child, here too a selection of a smaller $\alpha$, such as 0.3 , could be justified. This however leads to the distance between the course of the average age of a woman in Eastern Germany at an out-of wedlock birth and the course of the 0.35 -quantile as an estimated value for the average age of a mother at childbirth with the first child in the period from 1990 to 2008, being enlarged, and hence for this period this age could then be underestimated for the first child (possibly by a considerable margin). This consideration ultimately also leads for Eastern Germany as a kind of compromise solution to the selection of the 0.35 -quantile as an estimated value for the average age of a woman at the birth of the first child. What is more, it emerges in the context of the sensitivity analysis in Chapter Five that, where the 0.3-quantile is selected for this purpose, the indicators for the mean joint lifetime of multigenerational families only change slightly in terms of their level and the trends remain unchanged over time. 
course in the shape of a lying " $\mathrm{S}$ " is presumed. The generalised logistic function is formally described by the following equation:

$$
x_{\alpha}(t)=\beta_{1}+\frac{\beta_{2}}{1+e^{-\beta_{3} \cdot\left(t-\beta_{4}\right)}}
$$

The parameters $\beta_{1}, \beta_{2}, \beta_{3}$ and $\beta_{4}$ characterise the more detailed appearance of this function. Since overproportional and hence unrealistic upward trends are created for the given data, the shape of the generalised logistic function is verified via the constraints: $0 \leq \beta_{1} \leq \lambda \wedge \beta_{1}+\beta_{2}=\gamma \wedge \beta_{4} \geq 0$.

For the generalised logistic function, the parameter $\lambda$ determined a priori checks the maximum lower limit of the age of a mother at the birth of her first child. Since when observing Figure 2, this lower limit should be rather more towards 25 years than 30 , it is set for all calculations at a value above 25 years: that is at a value of 28 years. Parameter $\gamma$, which determines the maximum upper limit of the generalised logistic function, must also be defined a priori. Because this upper limit from the pure view of the courses of the estimated age of the mother at the birth of the first child according to Figure 2 is much less clearly visible, in the sense of scenario formation the calculations should be carried out with different values for $y$, parameter $y$ depending on the model variant lying in a value range of 27 to 36 . In the three main scenarios, $y$ takes on values of 30,32 and 34 years. With these scenarios it is presumed that the trend of the increase in the age of mothers at the birth of the (first) child of the past 30 years continues, but in the course of time a type of "natural" upper limit is reached. Hence, these variants ultimately postulate a period of how long the increase in the age of a mother at the birth of her children (or of her first child) remains stable - roughly outlined until 2020 for the scenario "increase in the maximum age of mothers at the birth of the first child first to 30 years" (short-term increase scenario), roughly until 2030 for the scenario "increase in the maximum first age of a mother at childbirth to 32 years" (medium-term increase scenario) and for instance by 2040 for the scenario "increase in the maximum age of mothers at the birth of the first child to 34 years" (longer-term increase scenario). As the results regarding the course of the indicators for the main scenarios will show, the acceleration in the increase of the maximum age of a mother at the birth of her first child leads to an acceleration in the overall downward trends of the indicators, and the pattern of the courses of the indicators shifts towards a later point in time. For this reason, in the context of this paper results for extreme increase scenarios, such as an increase in the maximum age of a mother at the birth of her first child to 36 or 38 , are not shown. Parameter $\beta_{3}$ determines slope and curvature, whilst parameter $\beta_{4}$ sets the point in time of the inflection point of the generalised logistic function. With the aid of the estimated parameters, finally, the estimated average age of a mother at the birth of her first child is projected for the years 2009 to 2060 . Since the calculations of the algorithm to ascertain the indicators for the mean joint lifetime of great grandmothers and great grandchildren, and of grandmothers and grandchildren, in the sense of a model calculation constitute a description pure and simple, nonsignificant results are ignored in the estimation of the parameters of the generalised logistic function. What is more, undesirable parameter constellations (e.g. negative 
values of parameters $\beta_{1}, \beta_{2}, \beta_{4}$ ) are ruled out via the constraints. As an adjustment period for a generalised logistic function, values for the years from 1972 to 2008 are used for Eastern Germany because from 1972 onwards the general trend of the previously-falling median age of a mother at the birth of a child changed towards a general trend of an increasing age of mothers at childbirth from then onwards. For the adjustment of a generalised logistic function to the data of Western Germany, the same period would suggest itself for these very considerations. However, a possible special effect arises as regards the average age of a mother at the birth of a child which might also be explained by the reunification of the two German states: The median age of a mother at the birth of a child in Western Germany increased more rapidly in the years prior to German reunification, and then slowed markedly until the mid-1990s. Thus, the course of this median age for the period from 1972 to 2008 took on the functional form of a double lying "S" type, which contradicts the intention of a logistic function. The data of the years from 1989 to 2008 for Western Germany were therefore used for pragmatic reasons and in order to guarantee the proper adjustment of a generalised logistic function. As a result, with regard to the interpretation of the estimated values for parameter $\beta_{4}$ the discrete time variable $t$ for Western Germany for 1989 and for Eastern Germany for 1972 is set at the value of one. $\beta_{1}^{(0)}=22, \beta_{2}^{(0)}=10, \beta_{3}^{(0)}=0, \beta_{4}^{(0)}=20$ are always selected as initial values of

the parameters in the iterative ascertainment of the maximum likelihood estimator. The estimated values of the parameters of the generalised logistic function belonging to the three main scenarios are listed for Western and Eastern Germany in Table 2 below, these being based on the data of the 0.35 -quantile age of a mother at the birth of a child described in section 3.1.

The courses of the adjusted and projected generalised logistic functions regarding the selection of the parameter $y$ of 30,32 and 34 years can be portrayed in

Tab. 2: Estimated values of the parameters of the generalised logistic function for the estimated average age of a mother at the birth of the first child in Western and Eastern Germany

\begin{tabular}{crrrrrr}
\hline Parameters & \multicolumn{3}{c}{ Western Germany } & \multicolumn{3}{c}{ Eastern Germany } \\
& $\gamma=30$ & $\gamma=32$ & $\gamma=34$ & $\gamma=30$ & $\gamma=32$ & $\gamma=34$ \\
\hline$\hat{\beta}_{1}$ & 26.065 & 26.005 & 25.974 & 21.758 & 21.601 & 21.488 \\
$\hat{\beta}_{2}$ & 3.935 & 5.995 & 8.026 & 8.242 & 10.399 & 12.512 \\
$\hat{\beta}_{3}$ & 0.195 & 0.163 & 0.149 & 0.131 & 0.109 & 0.097 \\
$\hat{\beta}_{4}$ & 20.052 & 24.047 & 27.022 & 31.177 & 34.701 & 37.870 \\
\hline
\end{tabular}

Source: Own calculations 
Fig. 3: $\quad$ Time course of the 0.35-quantile as an estimated value for the average age of a mother at the birth of the first child for Western and Eastern Germany, as well as the courses of the generalised logistic functions adjusted, and from 2009 projected, regarding the selection of the parameter $\mathrm{Y}(30,32,34$ years)
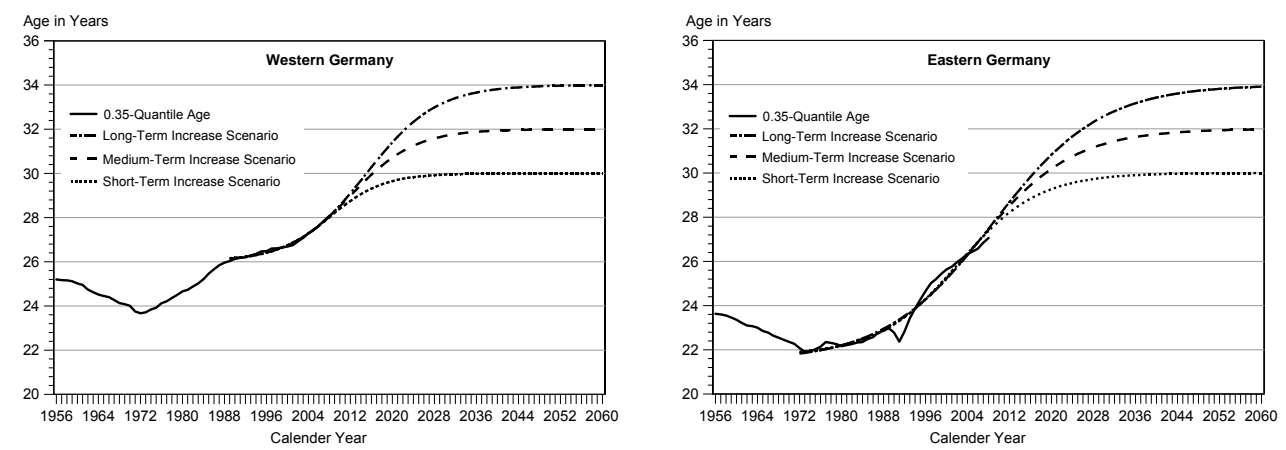

Source: Own calculations

Figure 3 using this information. To make the adjustment quality clear, Figure 3 contains the course of the 0.35 -quantile as an estimated value for the average age of a mother at the birth of the first child for Western and Eastern Germany.

As will be shown in the context of the sensitivity analysis in Chapter Five, only the (increasing) trend as a characteristic of the shape of the generalised logistic function of the average age of a mother at the birth of her first child projected from 2008 onwards exerts an influence on the indicator, albeit it tends to be slighter. The subordinate influence of the projected data for the average age of a mother at the birth of her first child is explained by the fact that many of the data required in the observation of three- and four-generation constellations are in the past. For this reason, even slight- to medium-serious misspecifications of the functional course for the projected average age of a mother at the birth of the first child on the results of the indicators tend to be marginal. This supports the pragmatic approach selected here.

\subsection{The algorithm to calculate the indicators for the joint lifetime of three- and four-generation families}

The indicator of the mean joint lifetime of a great grandmother (or grandmother) with her great grandchild (or grandchild) can be construed using these estimated values and using the mean residual life by birth cohorts and age of a person, which are taken from the cohort life table for Germany (published by the Federal Statistical Office in 2006) in variant V2 (higher life expectancy). The formal algorithm for the calculation of the indicator value for a certain point in time is presented below.

Since for the algorithm natural numbers are required at a number of places instead of positive real numbers, the positive real numbers regarding the natural number that is initially below this must be mathematically rounded off in these 
places. To this end, a rounding function is needed, for which in formal terms the socalled floor function is used. This is defined as follows: $[\mathrm{y}]:=\max _{\mathrm{k} \leq \mathrm{y}}(\mathrm{k}) \quad \begin{aligned} & \mathrm{k} \text {, originating from the volume of the whole numbers and } \mathrm{y} \text { being a } \\ & \text { real number. }\end{aligned}$

The residual life of a woman with birth cohort $a$ and at age $b$ is designated below with e $(a ; b)$. The algorithm can hence be portrayed as follows:

$$
\begin{aligned}
& \mathrm{x}_{\alpha}(\mathrm{t}) \\
& \mathrm{g}_{\mathrm{M}}:=\left[\mathrm{t}-\mathrm{x}_{\alpha}(\mathrm{t})\right] \quad \text { birth cohort of the mother } \\
& \mathrm{e}_{\mathrm{M}}:=\mathrm{e}\left(\mathrm{g}_{\mathrm{M}} ;\left\lfloor\mathrm{x}_{\alpha}(\mathrm{t})\right\rfloor\right) \quad \text { residual life of the mother at the birth of the child } \\
& x_{\alpha}\left(g_{M}\right) \quad \alpha \text {-quantile age of the grandmother at the birth of } \\
& g_{0}:=\left[g_{M}-x_{\alpha}\left(g_{M}\right)\right] \quad \text { birth cohort of the grandmother } \\
& \mathrm{e}_{\mathrm{O}}:=\mathrm{e}\left(\mathrm{g}_{\mathrm{O}} ;\left[\mathrm{x}_{\alpha}\left(\mathrm{g}_{\mathrm{M}}\right)\right]\right) \quad \text { residual life of the grandmother at the birth of the (6) } \\
& \mathrm{x}_{\alpha}\left(\mathrm{g}_{\mathrm{O}}\right) \quad \alpha \text {-quantile age of the great grandmother at the birth (7) } \\
& \mathrm{g}_{\mathrm{u}}:=\left[\mathrm{g}_{\mathrm{O}}-\mathrm{x}_{\alpha}\left(\mathrm{g}_{\mathrm{O}}\right)\right] \quad \text { birth cohort of the great grandmother } \\
& \mathrm{e}_{U}:=\mathrm{e}\left(\mathrm{g}_{\mathrm{U}} ;\left[\mathrm{x}_{\alpha}\left(\mathrm{g}_{\mathrm{O}}\right)\right\rfloor\right) \quad \text { residual life of the great grandmother at the birth of } \\
& \text { the grandmother }
\end{aligned}
$$

With these requirements for the algorithm for each time $t$, finally, the value $\mathrm{e}\left(\mathrm{g}_{\mathrm{u}} ; \mathrm{t}-\mathrm{gu}_{\mathrm{u}}\right)$

is placed as a mean joint lifetime of great grandmothers and great grandchildren and

$\mathrm{e}\left(\mathrm{g}_{\mathrm{o}} ; \mathrm{t}-\mathrm{g}_{\mathrm{o}}\right)$

as the average duration of existing grandmother/grandchild relationships. Steps (3), (6) and (9) are not needed to calculate the indicator. They are however also listed here since they are placed directly into the logic of the algorithm.

An example is to illustrate the approach to be followed: The time $t=2010$ for Western Germany (since this is the first time when one can calculate from the data both the mean joint lifetime for the constellation grandmother/grandchild and great grandmother/great grandchild). The 0.35 -quantiles of the calendar-year normed agespecific fertility rates are used as estimated values for the average age of a mother at the birth of the first child in a calendar year. A generalised logistic function with an upper limit of 32 years is presumed in order to project them from 2009 onwards. Because of the estimated parameters for this generalised logistic function, a projected mean age of a mother at birth of $x_{0.35}(2010)=28.51$ years emerges for 2010, and the corresponding year of birth is calculated via $t-x_{0.35}(2010)=2010-28.51=1981.49$ to be $g_{M}=[1981.49]=1981$. One can read from the cohort life table that a woman with the birth cohort 1981 has a mean residual life of $e_{M}=e(1981 ; 28)=60.65$ at the age of 28. For the calendar year 1981 the estimated average age of a mother at the birth of her first child is $\mathrm{x}_{0.35}(1981)=24.73$, the average birth cohort of the grandmother being de- 
termined via $g_{M}-x_{0.35}(1981)=1981-24.73=1956.27$ to be $g_{O}=[1956.27]=1956$. Analogue considerations reveal that the average age of a mother at the birth of her first child for the year 1956 is the value $x_{0.35}(1956)=25.20$. This provides an average birth cohort of the great grandmother of $g_{U}=[1930.80]=1930$. Now, the joint lifetime of grandmother and grandchild and great grandmother and great grandchild can be estimated for 2010 via the residual average life expectancy which for a woman with a birth cohort 1956 and an age of $2010-1956=54$ years (for the grandmother) and with a birth cohort 1930 and an age of $2010-1930=80$ years (for the great grandmother) can be read from the cohort life table:

- Mean joint lifetime of grandmother and grandchild:

$$
\mathrm{e}\left(\mathrm{g}_{\mathrm{O}} ; \mathrm{t}-\mathrm{g}_{\mathrm{O}}\right)=\mathrm{e}(1956 ; 54)=32.99 \text { years }
$$

- Mean joint lifetime of great grandmother and great grandchild:

$$
\mathrm{e}\left(\mathrm{g}_{\mathrm{U}} ; \mathrm{t}-\mathrm{g}_{\mathrm{U}}\right)=\mathrm{e}(1930 ; 80)=9.62 \text { years }
$$

Hence, the average framework data can be summed up in Table 3 below for a four-generation constellation (newborn; mother; grandmother; great grandmother) coming about in 2010. When interpreting the results, it should be taken into account that the calculations take place without consideration of infant mortality, and hence in the model of the joint lifetime only always ends with the death of the older generation.

By virtue of the fact that, in the context of the algorithm, the birth of a child at time $t$ is always placed at the beginning of the year and that mathematical rounding always takes place for the calculation of the birth cohort of the older generations in the generation composition, the algorithm tends to underestimate above all the birth cohort of the great grandmother by up to two years. This leads to a slight underestimation of the joint lifetime of great grandmother and great grandchild in a range of up to 0.2 years. This underestimation is tolerable for the interpretation of the figures and of the trend of the joint lifetime because of its small range in absolute terms. Were one to calculate for the above example calculation the birth cohort of the great grandmother by means of deducting from time the estimated or projected values for the average age of the mother, grandmother and great grandmother (here therefore $2010-28.51-24.73-25.20=1931.56$ ) and finally rounding the result to calculate the year of birth (here hence 1931), the value of 9.68 years would emerge for the indicator of the joint lifetime of great grandmother and great grandchild. However, this implicitly leads to a situation in which it is determined for the individual years at what time in the course of year $t$ a child is born on average. This is however just as unconvincing as for instance the arbitrary selection of the middle of the year as the average time for the birth of a child in the course of a year. Since, ultimately, no solution to this "problem of deciding between time of birth in the course of one year and rounding the age of the mother" is completely convincing, the path of "immediate rounding" on the basis of the negligible nature of the underestimation is finally also always selected here. If one uses the data of the cohort life table for Germany in variant V1 (lower life expectancy), the results on calculating the indicators change slightly towards a reduction in the joint lifetime of the child with his/her female ancestors. For the above example calculation, the data of the cohort life table for Germany in variant V1 provide a mean joint lifetime of the child with the 
Tab. 3: Average framework data of a four-generation constellation arising in 2010 for Western Germany

\begin{tabular}{lccc}
\hline & Age & Birth cohort & $\begin{array}{c}\text { Mean joint lifetime of the child and of } \\
\text { his/her female ancestors }\end{array}$ \\
\hline Child & 0 & 2010 & --- \\
Mother & 28 & 1981 & 60.65 years \\
Grandmother & 54 & 1956 & 32.99 years \\
Great grandmother & 80 & 1930 & 9.62 years \\
\hline
\end{tabular}

Source: Cohort life table for Germany (Statistisches Bundesamt, 2006); Own calculations

mother of 58.54 years, of the child with the grandmother of 31.76 years and of the child with the great grandmother of 9.29 years. Since the differences in the results in the two variants tend, firstly, to be marginal and, secondly, the trends emerging in the indicators are virtually identical, the results on the basis of variant V1 of the cohort life table for Germany are not presented in this paper.

The mean generation interval of great grandchild and great grandmother is obtained in the form of a by-product of the calculations of the difference in the birth cohorts. In the above example, this indicator shows a value of 80 years.

\section{$4 \quad$ Results}

As has already been described in section 3.2, the 0.35-quantile from the normed age-specific fertility rate distribution, separated for Western and Eastern Germany, is always used as an estimated value of the average age of a mother at the birth of her first child for 1956 to 2008. 30, 32 and 34 years are selected as an upper limit for the three main scenarios for the average age of a mother at the birth of her first child. Section five presents three further scenarios in a sensitivity analysis: The average age of the mother at the birth of her first child (1.) remains constant from 2008 onwards at the value used for 2008 , (2.) increases until 2030 to the age of 31.15 years and then falls in symmetry with the previous increase and (3.) runs mirror-symmetrical to the past from 2009 onwards. Additionally, the consequences selecting a different $\alpha$-quantile as the estimated value for the age of the mother at the birth of the first child is also illustrated (scenarios are presented for the selection of $\alpha=0.3$ and $\alpha=0.4)$. The calculations and the presentation of the results take place differentiated by Western and Eastern Germany in order to keep a particularly watchful eye on the differences in fertility conduct and the resulting consequences for the length of the joint lifetime of different generations of a family composition. By using the 2006 cohort life table for Germany from the Federal Statistical Office (variant V2), the assumptions and calculation models used for drawing them up are presumed to be valid. Equally, they are also presumed to be valid for 2009 to 2060 . The results calculated for the indicators are presented graphically on the basis of their acting as model calculations. In the context of the algorithm, the cohort life table is read 
from, for which one ultimately must use discrete figures for the age and the birth cohort, and an estimated value is calculated for the average age of a mother at the birth of her first child as a constant figure. Hence, a problem emerges that cannot be completely and finally satisfactorily mathematically solved via an algorithm, namely that the indicator of the mean joint lifetime of the different generations shows, over time, a shift of roughly one year. This may overlie the trends of the indicators, thus distorting them. However, in order to avoid these in the graphic presentation, fivepoint simple moving averages over time are calculated and presented in the figures for the indicators of the joint lifetimes of the various generations. Although some indicators of the joint lifetime of grandmother and grandchild can also already be calculated for some years prior to 1990 , for reasons related to the uniform graphical presentation, the time courses of these indicators are always presented for the period from 1990 to 2060 . The period from 2010 to 2060 is presented with regard to the joint lifetime of great grandmother and great grandchild for analogous reasons.

\subsection{Joint lifetime of grandmother and grandchild}

The time courses of the indicators for the joint lifetime of grandmother and grandchild for Eastern and Western Germany are presented in Figure 4. For the interpretation of the indicators at a certain point in time, it should be pointed out here that information on years in indicator values refers to the year of the birth of the (great) grandchild. The time courses for Western and Eastern Germany look very similar at first sight since the main tendency of the indicators is a downward trend over time. However, these show some marked differences in detail. The indicator for Western Germany initially rises up to its maximum of almost 35 years in 2000. This is caused above all by the fall in the average age of a mother at the birth of a child from 1956 to 1973. Due to the increasing age of the mother at the birth of the children since that time does the indicator fall for the joint lifetime of grandmother and grandchild since 2000. For Eastern Germany, where the reversal of the trend as to the average age of mothers at the birth of children can also be dated to 1973 , it is shown to be a minimum of 24.7 years and hence a much lower level in comparison to Western Germany. The ensuing increase in the average age of mothers at the birth of their children was much slower until German unification. Hence, the peak comparable with the courses of the indicators for Western Germany occurs is at an earlier time, and is not visible in Figure 4. The results of the algorithm however show that the indicators reach their maximum for Eastern Germany around 1990, with a value of approx. 38.8 years. The differences between the indicators for Western and Eastern Germany on reunification - that is around 1990 - can be mainly traced to the lower age of mothers in Eastern Germany at the birth of their (first) children in comparison to Western Germany. The massive changes in birth timing on the part of Eastern German women after German unity (that is until the mid-1990s), which are expressed in Figure 1 (cf. section 3.1) by the pronounced fall in the $\alpha$-quantiles of the normed fertility rate distributions have a milder impact on the indicator, delayed by a generation, as a result of a somewhat more pronounced fall in the period from 
Fig. 4: $\quad$ Course of time of the indicator of the joint lifetime of grandmother and grandchild for Western and Eastern Germany, 1990-2060 (five-point simple moving averages)

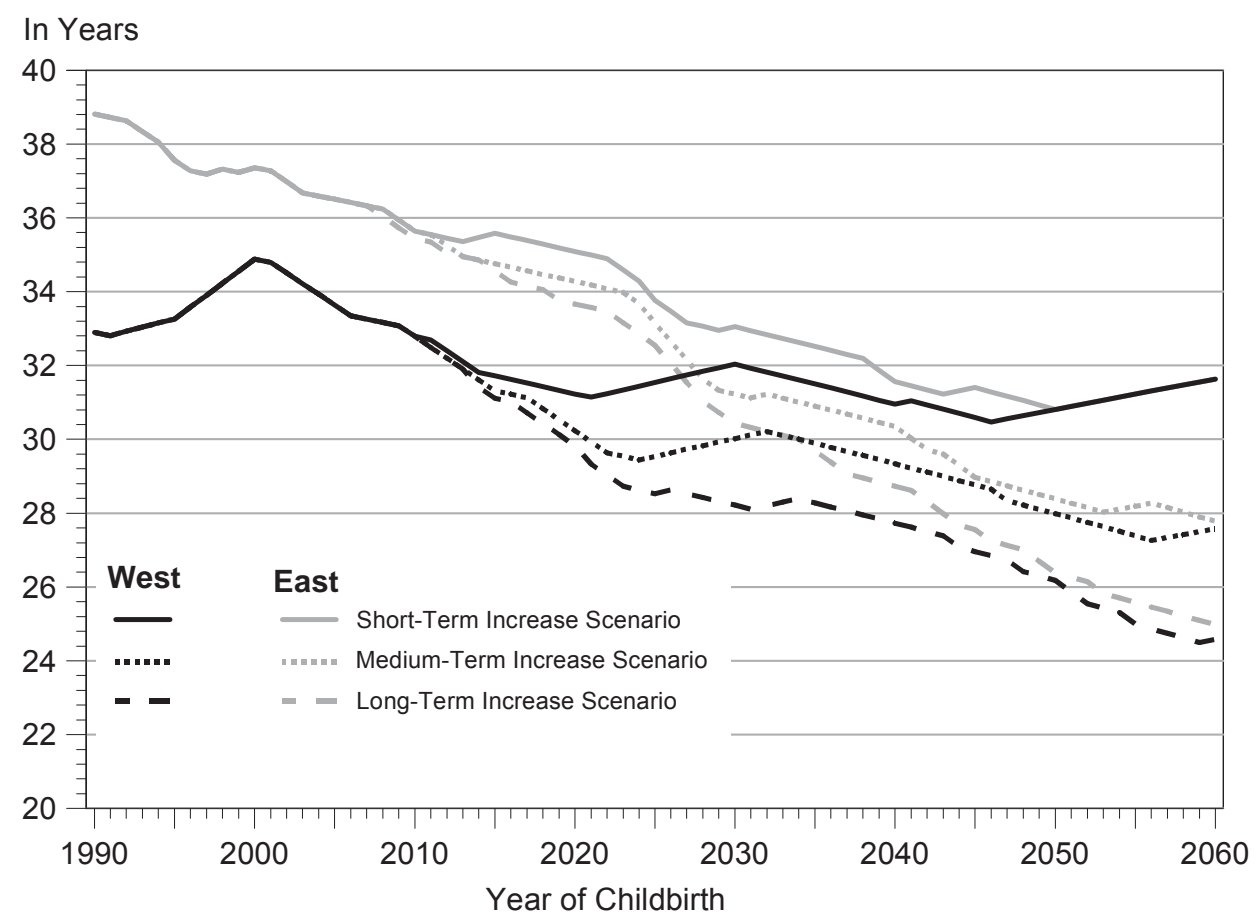

Source: Own calculations

2025 to 2030. The indicators for Western Germany show a stabilisation, or even a slight increase, in the jointly-spent years of grandmother and grandchild from a time - depending on the scenario - between 2045 and 2060. This stabilisation takes place in Eastern Germany delayed by roughly ten years. All figures regarding the courses of the indicators have in common that an increase in the maximum age of a mother at the birth of her first child would lead to an increase in the trends, falling in overall terms, and the pattern of the courses would move towards a later time (that is to the right).

\subsection{Joint lifetime of great grandmother and great grandchild}

Figure 5 below, which depicts the course over time of the indicators of the joint lifetime of great grandmother and great grandchild, reflects what has been shown previously for the joint lifetime of grandmother and grandchild with a time lag of approx. 30 years (that is of a generation). It should however be stressed that the falling trend reduces the indicator for the mean joint lifetime of great grandmother and great grandchild by time between 2050 and 2060 to a value of around six years. 
Fig. 5: Time course of the indicator of the joint lifetime of great grandmother and great grandchild for Western and Eastern Germany, 2010-2060 (five-point simple moving averages)

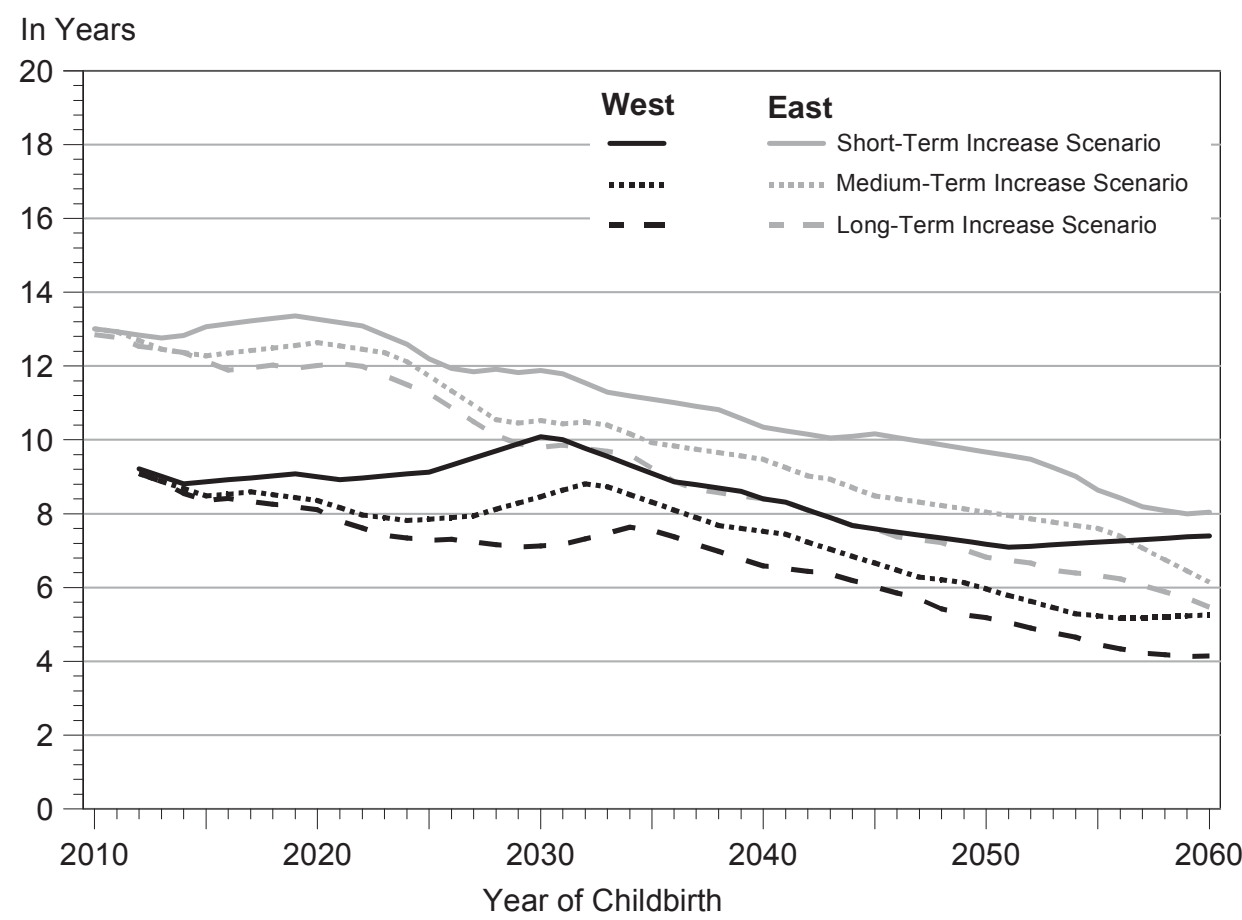

Source: Own calculations

Because of the time-lag effect of approx. 30 years between the indicators for the average duration of three- and four-generation constellations, it can be anticipated that the downward trend for the indicator with the four-generation constellations will continue until a time between 2080 and 2090.

\subsection{Mean generation interval between (great) grandmother and (great) grandchild}

As was already outlined in section 3.3, an indicator is created for the mean generation interval of great grandmother and great grandchild as a by-product of the algorithm to calculate the indicator for their mean joint lifetime. The graphic courses of this indicator for Western and Eastern Germany are visualised in Figure 6 below for the three main scenarios.

We recognise that - depending on the scenario - the indicator for the mean generation interval of great grandmother and great grandchild in the period from 2010 to 2060 increases by approx. 10 to 15 years, which corresponds to an average rise of 0.2 to 0.3 years $p$. a. If one compares this with the increase in average life expectancy in Western and Eastern Germany in recent years, which was roughly 0.2 years 
Fig. 6: Time course of the indicator for the mean generation interval of great grandmother and great grandchild and of grandmother and grandchild for Western and Eastern Germany (five-point simple moving averages, 2010-2060)
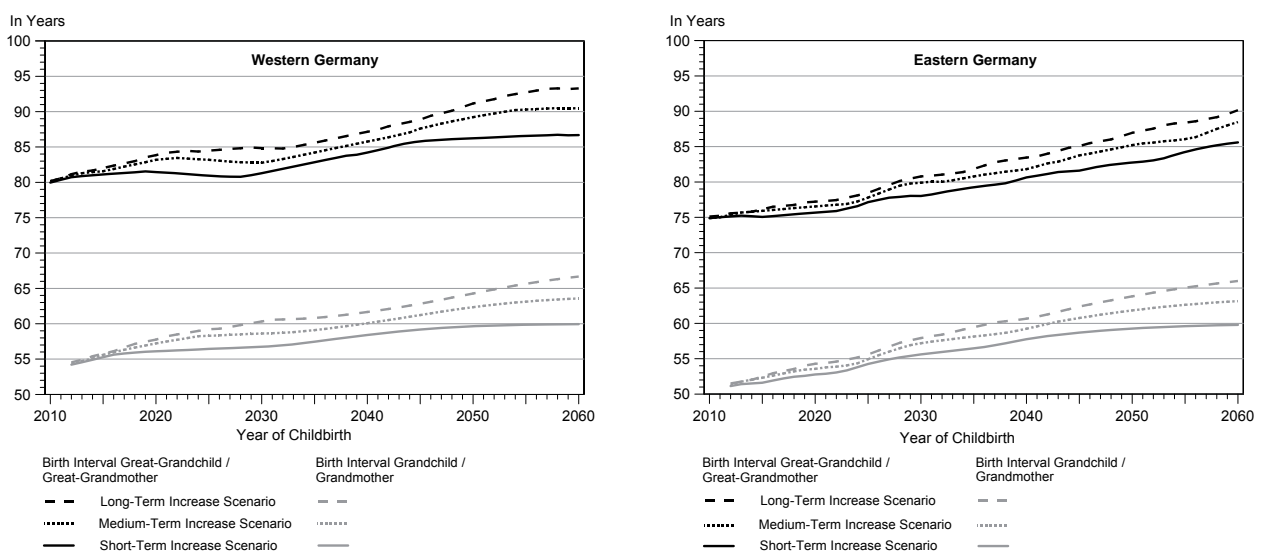

Source: Own calculations

p. a., this makes it clear that a further future increase in the age of mothers at the birth of the first child tends to overcompensate for the rise in average life expectancy. This indicates that the age of mothers at the birth of their children in the assessment of the joint lifetime presents the family composition of generations in family structures in comparison to the average life expectancy in the framework of the next 50 years as the higher factor to be emerged. The indicator of the mean generation interval of grandmother and grandchild increases by between five and 14 years in the period from 2010 to 2060, depending on the scenario. At the end of the period under observation, both indicators are virtually identical in the three main scenarios when it comes to a West-East comparison. In the medium-term scenario, the indicator of the average transitional age to great grandmotherhood in 2060 corresponds to a value of 88 years for Eastern Germany and 91 years for Western Germany, and the indicator regarding the average transitional age to grandmotherhood is 63 years for Eastern Germany and 64 years for Western Germany. All in all, a finding emerges that is similar to that of Höpflinger, Humme/ and Hugentobler (2006) for Switzerland (cf. section 2.3). Having said that, the indicators for the mean generation interval are currently around 10 years below the values measured for Switzerland; comparable generation intervals do not emerge for Germany for about another 50 years. 


\section{$5 \quad$ Sensitivity analysis}

This section presents results for the indicators with alternative scenarios in order to show the reaction of the indicators to changes in the assumptions if no ongoing increase in the maximum age of mothers at the birth of the first child is presumed. To this end, a calculation is first carried out with another selection for the $\alpha$-quantile ( $\alpha$ of 0.3 or 0.4 , respectively) as an estimated value for the average age of a mother at the birth of the first child. With regard to these quantiles, Table 4 contains the corresponding estimation parameters of the generalised logistic function with a maximum limit for the average age of a mother at birth of the first child of 32 years.

Additionally, for the keywords "constant", "parabola" and "symmetry scenario" three further scenarios are listed. In the framework of the constant scenario, the

Tab. 4: $\quad$ Parameters of the generalised logistic function for the estimated average age of a mother at the birth of the first child in Western and Eastern Germany (under sub-condition $\gamma=32$ ) for the selection of the 0.3- and 0.4-quantiles

\begin{tabular}{ccccc}
\hline Parameters & \multicolumn{2}{c}{ Western Germany } & \multicolumn{2}{c}{ Eastern Germany } \\
& $\alpha=0.3$ & $\alpha=0.4$ & $\alpha=0.3$ & $\alpha=0.4$ \\
\hline$\hat{\beta}_{1}$ & 25.372 & 26.561 & 21.022 & 22.185 \\
$\hat{\beta}_{2}$ & 6.628 & 5.439 & 10.978 & 9.815 \\
$\hat{\beta}_{3}$ & 0.190 & 0.144 & 0.100 & 0.119 \\
$\hat{\beta}_{4}$ & 24.770 & 22.567 & 36.438 & 33.256 \\
\hline
\end{tabular}

Source: Own calculations

Fig. 7: Time courses of the average age of a mother at the birth of her first child for the medium-term increase, constant, parabola and symmetry scenarios for Western and Eastern Germany
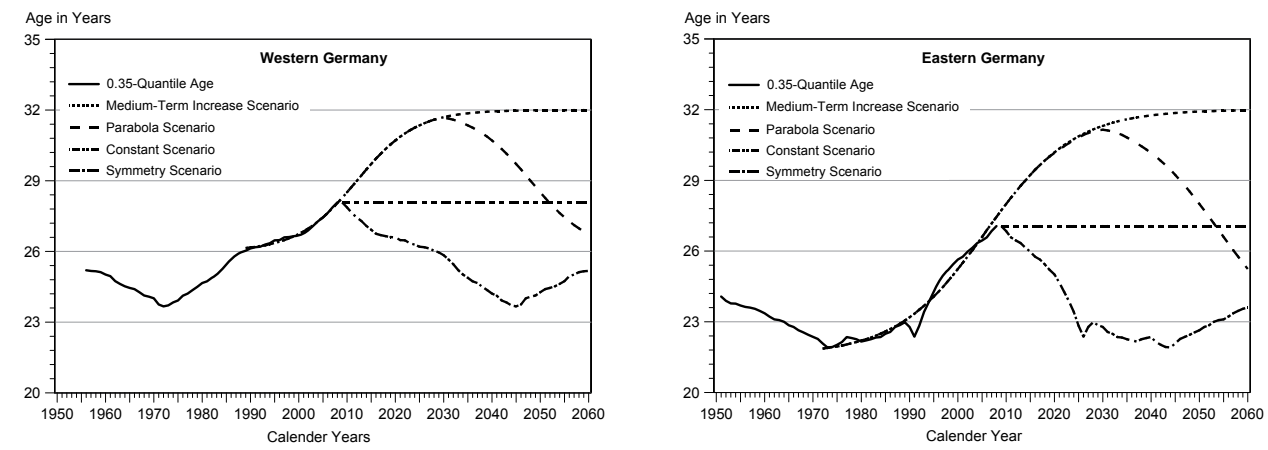

Source: Own calculations 
average age of a mother at the birth of the first child is kept constant for all future years in accordance with the corresponding 0.35 -quantile from the normed fertility rate distribution of 2008. This value corresponds to the age of 28.08 years for Western Germany and to the age of 27.06 years for Eastern Germany. The parabola scenario presumes a future course of the average age of a mother at the birth of the first child until the year 2030 in accordance with the medium-term increase scenario (that is a selection of $\alpha=0.35$ and $y=32$ ). From 2031 onwards, the average age of a mother at the birth of her first child runs mirror-symmetrical to the course of the medium-term increase scenario. The symmetry scenario presumes from 2009 onwards a mirror-symmetrical course to the trend of the average age of a mother at the birth of her first child for the years 1956 to 2008. Figure 7 documents the courses of this average age of a mother at the birth of her first child for the five scenarios in Western and Eastern Germany.

Fig. 8: Time course of the indicator for the joint lifetime of grandmother and grandchild for Western and Eastern Germany for the medium-term increase scenario on the basis of various $\alpha$-quantiles regarding the selection $\alpha=0.3, \alpha=0.35$ and $\alpha=0.4$ (five-point simple moving averages, 1990-2060)

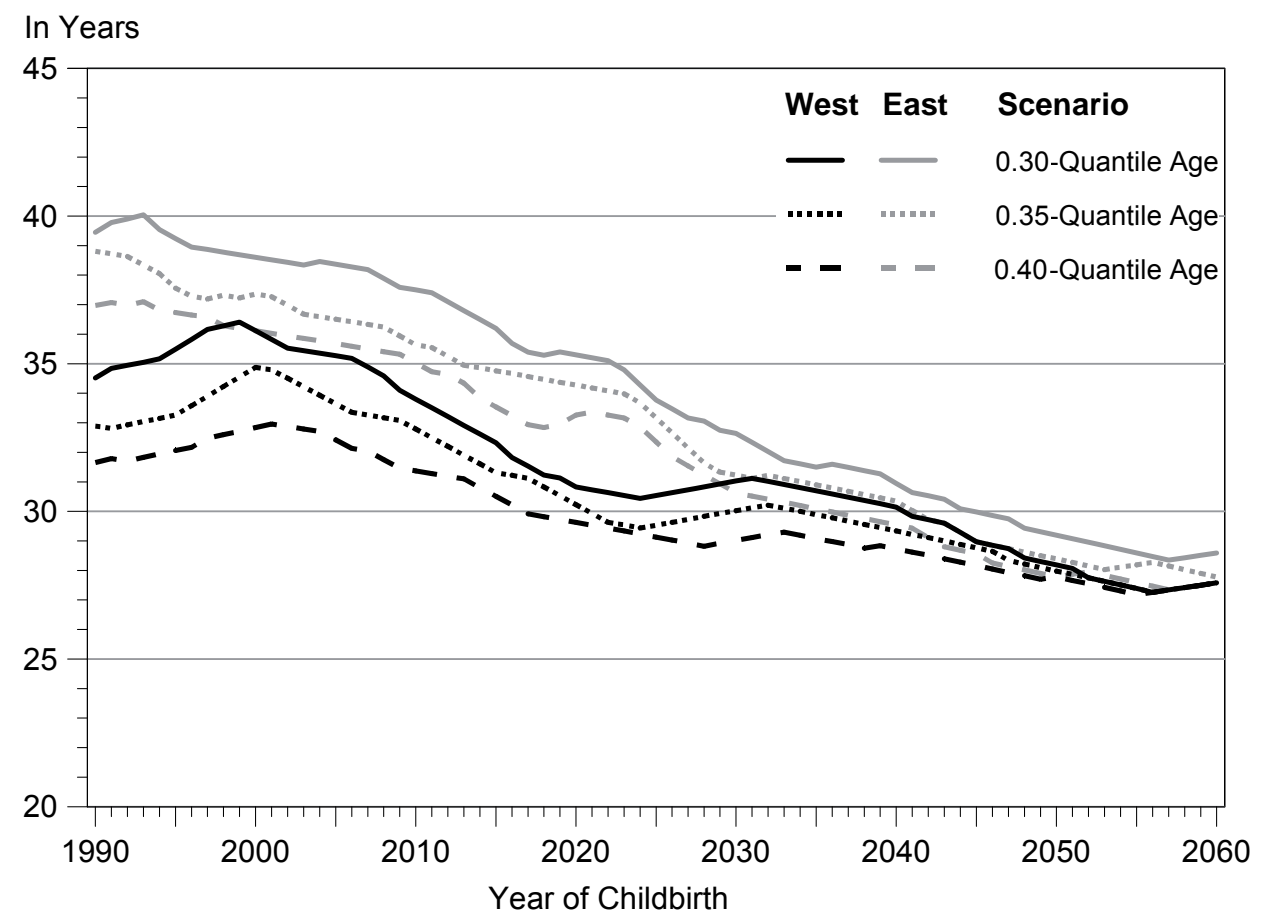

Source: Own calculations 
Fig. 9: Time course of the indicator for the joint lifetime of great grandmother and great grandchild for Western and Eastern Germany for the mediumterm increase scenario on the basis of various $\alpha$-quantiles regarding the selection $\alpha=0.3, \alpha=0.35$ and $\alpha=0.4$ (five-point simple moving averages, 2010-2060)

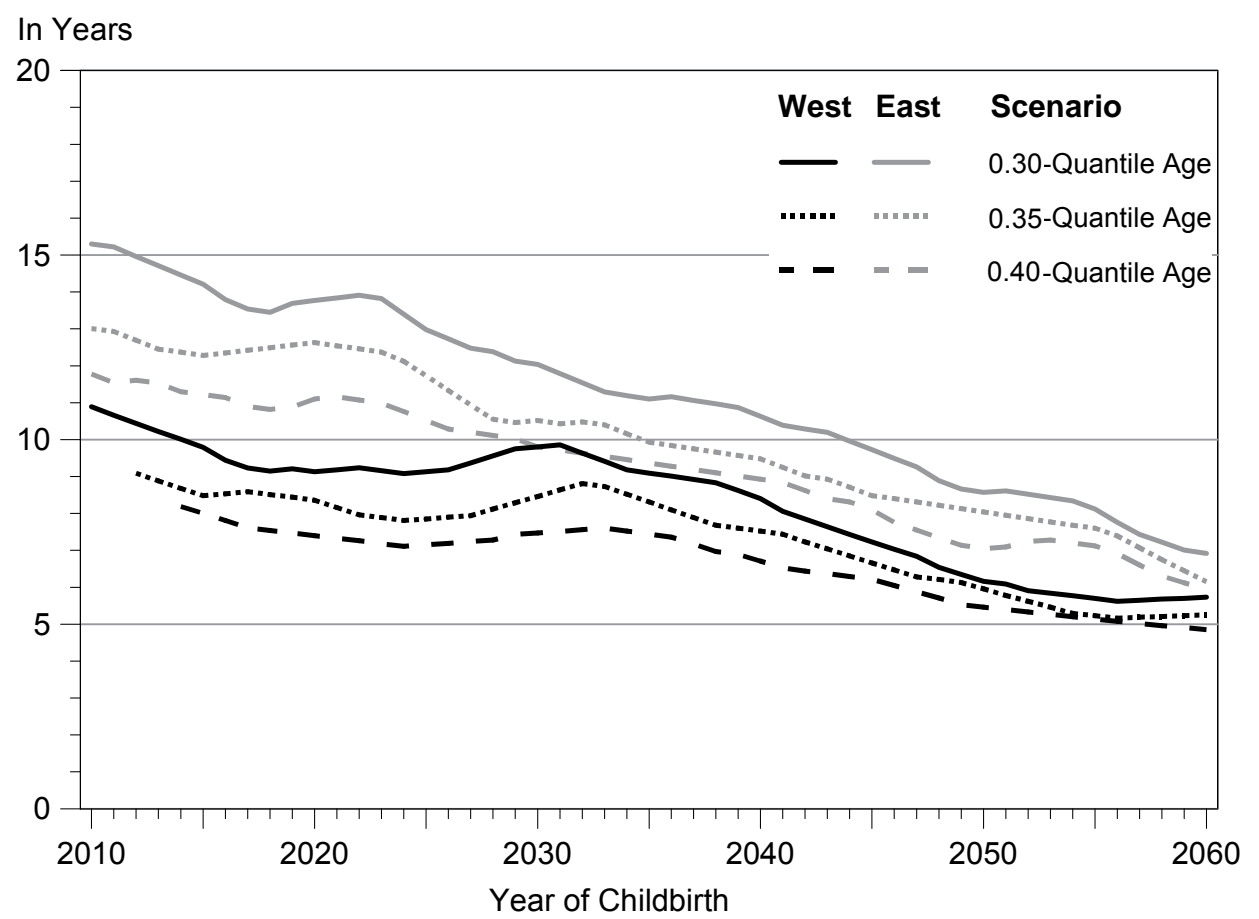

Source: Own calculations

As can be recognised in Figures 8 and 9, a different selection of an a-quantile as an estimated value for the average age of a mother at the birth of the first child only leads to a vertical shift in the indicators. The absolute distance between the indicators at a certain point in time, and/or where $\alpha=0.3$ and $\alpha=0.4$ is selected, is always less than four years and diminishes over time. The courses show that the selection of $\alpha$ has little influence on the trends of the indicators, and hence tends to be insignificant for their interpretation.

A more pronounced influence on the trends of the indicators is exerted by the selection of the future trend for the average age of a mother at the birth of the first child. This is revealed in the observation of the indicators for constant, parabola and symmetry scenarios, as can be observed in Figures 10 and 11.

One only recognises that merely the symmetry scenario, which can be referred to as more improbable and which supposes a considerable fall in the age of women at the birth of the first child, exerts pronounced, immediate influences on the indica- 
Fig. 10: Time course of the indicator for the joint lifetime of grandmother and grandchild for Western and Eastern Germany for the medium-term increase, constant, parabola and symmetry scenarios (five-point simple moving averages, 1990-2060)

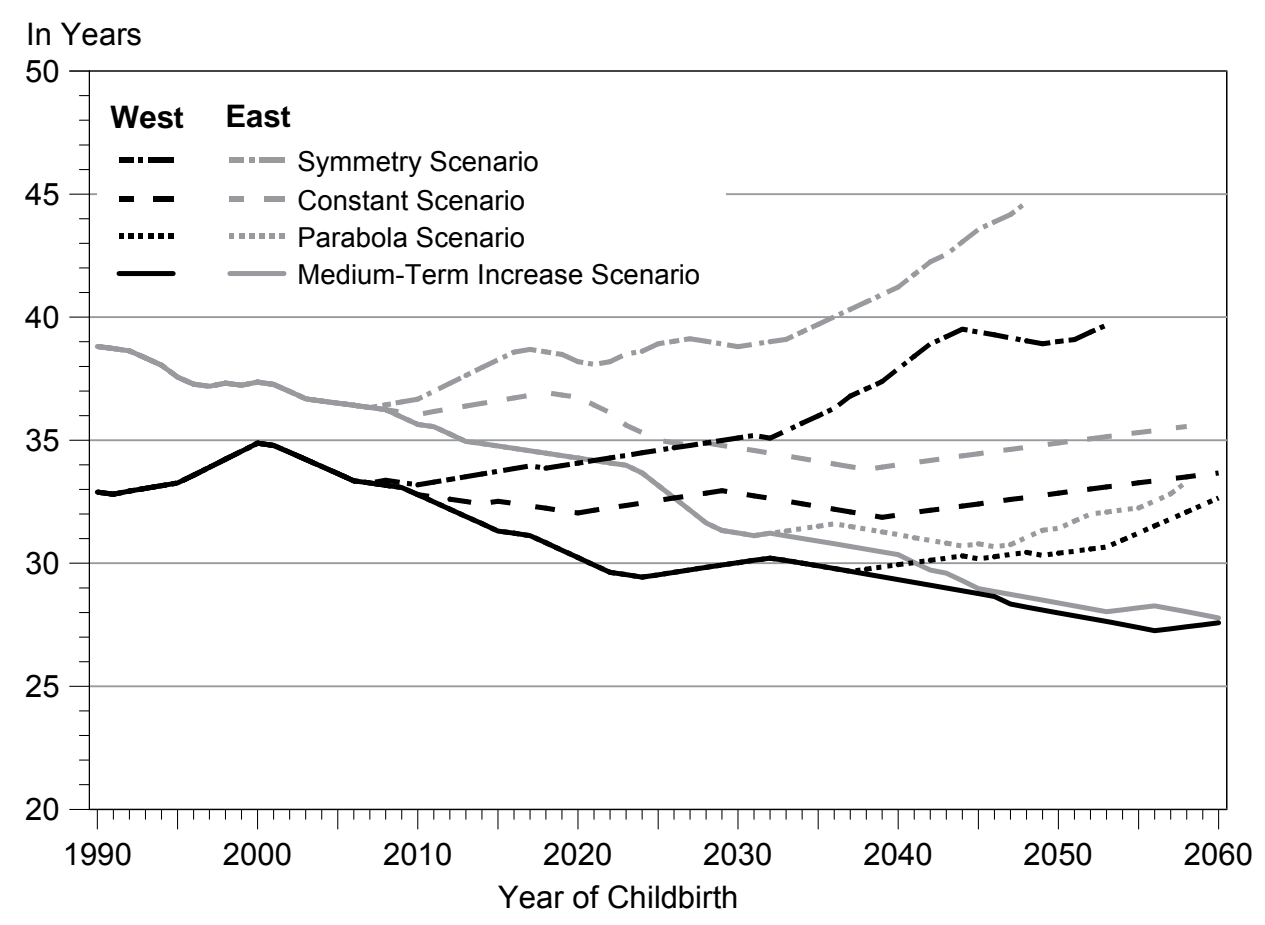

Source: Own calculations

tors. In the other two scenarios the trends of the indicators persists in the medium term - that is until about 2030. The constant scenario leads in the long term - that is here until 2060 - to a settling down of the indicators at a stable level. However, as soon as the average age of the mothers at the birth of their first children starts to fall again over time, the parabola scenario suggests that the indicators for the mean joint lifetime of three- and four-generation families increase again with a lag of approx. one generation. 
Fig. 11: Time course of the indicator for the joint lifetime of great grandmother and great grandchild for Western and Eastern Germany for the mediumterm increase, constant, parabola and symmetry scenarios (five-point simple moving averages, 2010-2060)

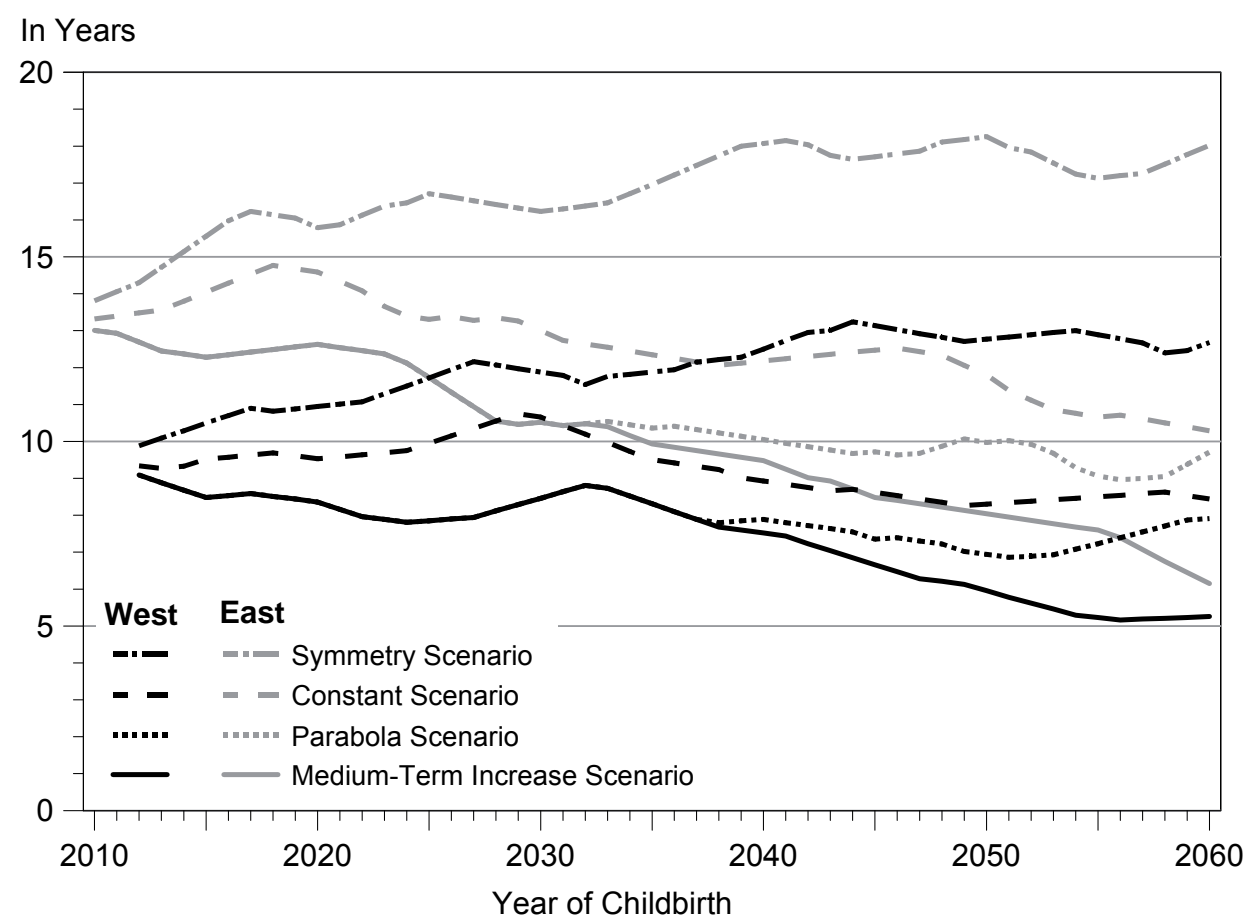

Source: Own calculations

\section{Summary and discussion}

This article aimed to make a contribution towards the academic debate on the question of whether the shares of four-generation families in Germany in future will increase, remain constant or diminish concerning an aspect which has received relatively little consideration in the past, namely the mean joint lifetimes of three- and four-generation families. In historical terms, the cohabitation of several generations lasts only a very short time since the three-generation family did not become a normal case in the composition of generations in family structure until the second half of the 20th Century. By observing the historical developments in multiple-generation families, whilst at the same time considering the development of mortality and fertility for Germany, the decisive influencing factors emerge on the composition of generations in family structures: The pronounced fall in mortality from the end of the 19th Century onwards - first with children and after the Second World War above all in the higher age cohorts, the changing timing of births and the growing childlessness, as well as finally the changes in living arrangements 
(more lone parents, more divorces, more step and patchwork families). Using some of the larger surveys which have been carried out in the past 20 years (age survey, SOEP, OASIS, SHARE, GGS), it is possible to roughly estimate the current circumstances of multiple-generation constellations for Germany: Roughly half of respondents live in three-generation families from middle age onwards; approximately one-quarter to one-fifth live in two-family constellations and a maximum of between one in 5 to 10 respondents lives in a four-generation family. However, neither a development over time, nor a forecast for future developments in the shares of multiple-generation families can be generated from these data. Additionally, it is not possible to obtain either from the survey data, or from the official statistics for Germany, valid estimate results relating to the joint lifetime of several generations of a family.

As has been shown in the framework of this article, it is however possible on the basis of the data of a cohort life table and historic age-specific fertility rates to derive indicators for the mean joint lifetimes of three- and four-generation families. These indicators aim to provide an idea of the scale and the trends of this joint lifetime of three- and four-generation families in Germany. However, the intention is not to study arbitrary family compositions of generations in family structures regarding their joint average lifetime, but on the basis of the complicated data available it is necessary to restrict to the female line and to trace it in each case to the firstborn child. Hence, the indicators are only suited to study the joint average lifetime of great grandmothers with their first-born great grandchildren and grandmothers with their first-born grandchildren over time.

Since the average age of mothers at the birth of their first child in the required time length and differentiated by Western and Eastern Germany is not available via official data, in the context of this observation the data required are estimated via a suitably-selected $\alpha$-quantile of the calendar-year (normed) age-specific fertility rate distribution. The calculation via the female line is also a kind of "upper limit" for the joint lifetime of three- and four-generation compositions of generations in family structures, since the lower life expectancy of men and their higher age on starting a family indicates a shorter mean joint lifetime of (great) grandfathers with their (great) grandchildren than is the case with the female line. The indicators were calculated separated for Western and Eastern Germany, since the average age of women in childbirth between the two regions developed very differently in the past, and to the present day also is roughly one year lower in Eastern Germany than in Western Germany. For the period from 1990 to 2008 it is possible to properly estimate with one indicator the maximum mean joint lifetime of three-generation families. The indicator for the four-generation constellations, by contrast, can only be ascertained if future values of the average age of a mother at the birth of the first child are available. The same applies to the three-generation indicator from 2009 onwards. Since for this the average age of a mother at the birth of the first child on the basis of a suitable model had to be projected into the future, the indicators of the mean joint lifetime of three- and four-generation families from 2009 onwards act as model calculations. The generalised logistic function, with constraints, has been selected as an adjustment and projection model for the average age of a mother 
at the birth of her first child; above all, the maximum age at the birth of the first child has been checked when it comes to the constraints. Several scenarios were calculated in the context of the model calculations, whereas in the medium variant the 0.35 -quantile, as well as a maximum age at birth of 32 years, was selected to calculate the age of the mother at the birth of the first child. A sensitivity analysis with other, certainly also extreme, controversial assumptions has shown that the indicators react to another selection of the a-quantile mainly with a vertical shift, but that the trends remain unchanged. Since, for a certain point in time $t$, the intergenerational family relationship is observed retrospectively, errors in the selection regarding the projection of the average age of a mother at the birth of her first child have a very gradual effect, here too being defined mainly through vertical shifts in the indicators. Only the selection of an extreme variant, and one which appears rather improbable, for the future development of the average age of a mother at the birth of the first child - in this case the scenario of an immediate trend reversal taking place mirror-symmetrically in the time range of 1972 to 2008, that is the age of mothers in childbirth falling immediately - leads after a short response time of approx. 10 years to a pronounced change in the trends of the indicators for the mean joint lifetimes of three- and four-generation families. All in all, the following results may be concluded from the calculations put forward here:

1) The calculations in Western Germany show an increase in the lifetime spent jointly in three generations up to roughly 35 years in 2000 . The average age of mothers at the birth of their children, which increased from roughly 1973 onwards, currently becomes noticeable via the gradual fall in the joint lifetime of grandma and her grandchildren. Depending on the selected maximum age of mothers at the birth of their first child, a faster (at 32 years) or later (at 34 years) stabilisation of the joint lifetime takes place, at a value of roughly 30 years. The jointly-spent years of four generations show a similar trend - but postponed roughly 30 years into the future. The highest values of joint lifetimes here, for instance, must be anticipated roughly between 2030 and 2040 (between seven and 10 years, depending on the selected age of a mother in childbirth), after which the downward trend will continue, under the presumed conditions, into the eighties of this century.

2) For Eastern Germany, the maximum of the jointly-spent years of life of three generations lies at the beginning of the observation period 1990 (at almost 40 years). From then onwards, a continuously-falling trend can be identified which is only influenced in the rapidity of the descent by the selected maximum age at birth. This development is caused by the much slower increase in the average age of a mother at childbirth in comparison to Western Germany, which did not considerably accelerate until after 1990. This is then reflected between 2025 and 2030 by a somewhat more rapid fall in the joint lifetime of grandma and her first-born grandchild. The average number of years spent jointly by great grandmothers and their great grandchildren is likely to peak around 2020. It may currently be roughly one-and-a-half times as high as in 
Western Germany, since the lower age of a mother in childbirth in the East adds up over several generations, whilst the mortality differences are only minimal. One may also anticipate a fall in the joint lifetime of four-generation families in Eastern Germany after 2020, albeit starting at a higher level.

At this point, however, it is necessary to point out once more that these are projections of the joint lifetime and not a statement that these theoretically-possible multiple-generation constellations will actually be experienced. To this end, sociostructural differentiations would be just as necessary as the consideration of the fact, as childlessness increases, above all in Western Germany, generation lines will break off (cf. section 2.4). To sum it up, however, it becomes evident that it is not sufficient to conclude from the longer life expectancy a generally longer joint lifetime of the generations and an increase in the number of four-generation families. The daughters of the now still relatively young grandmother generations, with their delayed family formation, will increase the intergenerational age intervals and enter grandparenthood at a much higher age than their mothers' generations. To what degree this process can be reduced by rising life expectancy is questionable. The three-generation family is likely to also remain the decisive family generation constellation in this century.

\section{References}

Bengtson, Vern; Rosenthal, Carolyn; Burton, Linda, 1990: Families and Aging: Diversity and Heterogeneity. In: Binstock, Robert H.; George, Linda K. (Eds.): Handbook of Aging and the Social Sciences. San Diego: Academic Press Inc.: 263-287

Bengtson, Vern L., 2001: Beyond the Nuclear Family: The Increasing Importance of Multigenerational Bonds. In: Journal of Marriage and Family 63,1: 1-16

Bengtson, Vern L.; Schaie, K. W.; Burton, Linda M. (Eds.), 1995: Adult Intergenerational Relations. Effects of Societal Change. New York: Springer

Bengtson, Vern L.; Schütze, Yvonne, 1992: Altern und Generationenbeziehungen: Aussichten für das kommende Jahrhundert. In: Baltes, Paul B.; Mitte/straß, Jürgen (Eds.): Zukunft des Alterns und gesellschaftliche Entwicklung. Forschungsbericht 5. Berlin/ New York: Walter de Gruyter: 492-517

Bien, Walter et al., 1994: Die Anlage der Mehrgenerationenstudie: Theoretische Grundüberlegungen, Hauptfragestellungen und methodische Umsetzung. In: Bien, Walter (Eds.): Eigeninteresse oder Solidarität. Beziehungen in modernen Mehrgenerationenfamilien. DJI: Familien-Survey 3. Opladen: Leske + Budrich: 29-46

BMFSFJ (Bundesministerium für Familie, Senioren, Frauen und Jugend), 2009: Zentrale Daten und Aussagen zum Familienreport mit Quellenhinweisen. Pressemitteilung vom 16. Februar 2009. Berlin. Online verfügbar unter www.bmfsfj.de

Eggen, Bernd; Rupp, Marina, 2007: Kinderreichtum - Eine Ausnahme in der neueren Geschichte? In: Statistisches Monatsheft Baden-Württemberg 2007,3: 6-14

Ehmer, Josef, 2004: Bevölkerungsgeschichte und historische Demographie 1800 - 2000. Enzyklopädie deutscher Geschichte 71. München: R. Oldenbourg 
Farkas, Janice I.; Hogan, Dennis P., 1995: The Demography of Changing Intergenerational Relationships. In: Bengtson, Vern L.; Schaie, K. Warner; Burton, Linda M. (Eds.): Adult Intergenerational Relations. Effects of Societal Change. New York: Springer: $1-25$

Hagestad, Gunhild O.; Herlofson, Katharina, 2007: Micro and Macro Perspectives on Intergenerational Relations and Transfers in Europe. Report from United Nations Expert Group Meeting on Social and Economic Implications of changing Population Age Structures. New York: United Nations

Hoff, Andreas, 2006: Intergenerationale Familienbeziehungen im Wandel. In: TeschRömer, Claus; Engstler, Heribert; Wurm, Susanne (Eds.): Altwerden in Deutschland. Sozialer Wandel und individuelle Entwicklung in der zweiten Lebenshälfte. Wiesbaden: VS Verlag für Sozialwissenschaften: 231-287

Höpflinger, Francois; Hummel, Cornelia; Hugentobler, Valérie, 2006: Enkelkinder und ihre Grosseltern. Intergenerationelle Beziehungen im Wandel. Zürich: Seismo Verlag

Höpflinger, Francois, 2008: Demographischer Wandel der Generationenverhältnisse. [http://www.hoepflinger.com/fhtop/fhgenerat1E.html, 10-05-2010]

Kohli, Martin; Künemund, Harald; Lüdicke, Jörg, 2005: 4.1 Family Structure, Proximity and Contact. In: Börsch-Supan, Axel et al. (Eds.): Health, Ageing and Retirement in Europe. First Results from the Survey of Health, Ageing and Retirement in Europe. Mannheim: 164-170

Kohli, Martin et al., 2005: 6 Generationenbeziehungen. In: Kohli, Martin; Künemund, Harald (Eds.): Die zweite Lebenshälfte. Gesellschaftliche Lage und Partizipation im Spiegel des Alters-Survey. Opladen: Leske + Budrich: 176-211

Lauterbach, Wolfgang, 1994: Lebenserwartung, Lebensverläufe und Generationenfolgen in Familien oder: Wie lange kennen sich familiäre Generationen? Universität Konstanz, Sozialwissenschaftliche Fakultät, Forschungsschwerpunkt "Gesellschaft und Familie". Arbeitspapier 10. Konstanz

Lauterbach, Wolfgang, 1995a: Die gemeinsame Lebenszeit von Familiengenerationen. In: Zeitschrift für Soziologie 24,1: 22-41

Lauterbach, Wolfgang, 1995b: Familiengenerationen in modernen Gesellschaften oder: Der Rhythmus der Generationen. Universität Konstanz, Sozialwissenschaftliche Fakultät, Forschungsschwerpunkt "Gesellschaft und Familie“. Arbeitspapier 17. Konstanz

Lauterbach, Wolfgang, 2000: Kinder in ihren Familien. Lebensformen und Generationengefüge im Wandel. In: Lange, Andreas; Lauterbach, Wolfgang (Eds.): Kinder in Familie und Gesellschaft zu Beginn des 21sten Jahrhunderts. Der Mensch als soziales und personales Wesen 18. Stuttgart: Lucius und Lucius: 155-186

Lauterbach, Wolfgang, 2002: Großelternschaft und Mehrgenerationenfamilien - soziale Realität oder demographischer Mythos? In: Zeitschrift für Gerontologie und Geriatrie 35: 540-555

Lauterbach, Wolfgang, 2004: Die multilokale Mehrgenerationenfamilie. Zum Wandel der Familienstruktur in der zweiten Lebenshälfte. Familie und Gesellschaft 13. Würzburg: Ergon

Lowenstein, Ariela; Ogg, Jim, 2003: OASIS. Old Age and Autonomy: The Role of Service Systems and Intergenerational Family Solidarity - Final Report. 2003 [http://oasis. haifa.ac.il/resources.htm, 06-05-2010]

Lüscher, Kurt; Liegle, Ludwig, 2003: Generationenbeziehungen in Familie und Gesellschaft". UTB 2425. Konstanz: UVK 
Luy, Marc, 2002: Warum Frauen länger leben - Erkenntnisse aus einem Vergleich von Kloster- und Allgemeinbevölkerung, Materialien zur Bevölkerungswissenschaft 106. Wiesbaden: Bundesinstitut für Bevölkerungsforschung

Mathews, T. J.; Hamilton, Brady E., 2009: Delayed Childbearing. More Women Are Having Their First Child Later in Life. U.S. DEPARTMENT OF HEALTH AND HUMAN SERVICES, Centers for Disease Control and Prevention; National Center for Health Statistics. NCHS Data Brief 21. Hyattsville. [http://www.cdc.gov/nchs/data/databriefs/db21. pdf, 03-08-2010]

Mitterauer, Michael, 2009: Sozialgeschichte der Familie. Kulturvergleich und Entwicklungsperspektiven. Basistexte Wirtschafts- und Sozialgeschichte 1. Wien: Braumüller Universitäts Verlagsbuchhandlung

Nave-Herz, Rosemarie, 2005: Die Mehrgenerationenfamilie unter familienzyklischem Aspekt. In: Steinbach, Anja (Eds.): Generatives Verhalten und Generationenbeziehungen. Festschrift für Bernhard Nauck zum 60. Geburtstag. Wiesbaden: VS Verlag für Sozialwissenschaften: 47-60

Putney, Norella M.; Bengtson, Vern L., 2003: Intergenerational Relations in Changing Times. In: Mortimer, Jeylan T.; Shanahan, Michael J. (Eds.): Handbook of the Life Course. New York/u.a.: Kluwer Academic, Plenum Publishers: 149-164

Statistisches Bundesamt, 1993: Sonderreihe mit Beiträgen für das Gebiet der ehemaligen DDR. Heft 3 Bevölkerungsstatistische Übersichten 1946 bis 1989. Wiesbaden

Statistisches Bundesamt, 1996: Sonderreihe mit Beiträgen für das Gebiet der ehemaligen DDR. Heft 28 Bevölkerungsstatistische Übersichten 1946 bis 1989 (Teil II). Wiesbaden

Statistisches Bundesamt, 2006: Generationensterbetafeln für Deutschland, Modellrechnungen für die Geburtsjahrgänge 1871-2004. Wiesbaden

Szydlik, Marc; Künemund, Harald, 2009: Generationen aus Sicht der Soziologie. In: Künemund, Harald; Szydlik, Marc (Eds.): Generationen. Multidisziplinäre Perspektiven. Martin Kohli zum 65. Geburtstag. Wiesbaden: VS Verlag für Sozialwissenschaften: 7-22

Toutenburg, Helge; Heumann, Christian, 2008: Deskriptive Statistik: Eine Einführung in Methoden und Anwendungen mit R und SPSS. Berlin: Springer

Uhlenberg, Peter, 1995: Commentary: Demographic Influences on Intergenerational Relationships. In: Bengtson, Vern L.; Schaie, K. Warner; Burton, Linda M. (Eds.): Adult Intergenerational Relations. Effects of Societal Change. New York: Springer: 19-25

Uhlenberg, Peter, 1996: Mortality Decline in the Twentieth Century and Supply of Kin Over the Life Course. In: The Gerontologist 36,5: 681-685

Uhlenberg, Peter; Kirby, James B., 1998: Grandparenthood Over Time: Historical and Demographic Trends. In: Szinovacz, Maximiliane E. (Eds.): Handbook on Grandparenthood. Greenwood: Westport: 23-39

Wernhart, Georg et al., 2008: Drei Generationen - eine Familie. Austauschbeziehungen zwischen den Generationen aus Sicht der Großeltern und das Altersbild in der Politik. Familienforschung - Schriftenreihe des Österreichischen Instituts für Familienforschung 18. Innsbruck/Wien/Bozen: StudienVerlag 
Translated from the original text by the Federal Institute for Population Research, for information only. The reviewed and author's authorised original article in German is available under the title

"Zur Entwicklung der durchschnittlichen gemeinsamen Lebenszeit von Drei- und Vier-Generationen-Familien in West- und Ostdeutschland - Eine Modellrechnung", DOI 10.4232/10.CPoS-201101de or URN urn:nbn:de:bib-cpos-2011-01de9, at http://www.comparativepopulationstudies.de.

Dr. Manfred G. Scharein ( $₫)$, Dr. Evelyn Grünheid.

Federal Institute for Population Research, Wiesbaden, Germany.

E-Mail: manfred.scharein@destatis.de, evelyn.gruenheid@destatis.de

URL: http://www.bib-demografie.de 


\section{Comparative Population Studies - Zeitschrift für Bevölkerungswissenschaft}

wWw.comparativepopulationstudies.de

ISSN: 1869-8980 (Print) - 1869-8999 (Internet)

Published by / Herausgegeben von

Prof. Dr. Norbert F. Schneider

Layout and print: Federal Institute for Population Research, Wiesbaden (Germany)

Managing Editor / Redaktion

Frank Swiaczny

\section{Copy Editor / Schlussredaktion}

Dr. Evelyn Grünheid

\section{Scientific Advisory Board / Wissenschaftlicher Beirat}

Jürgen Dorbritz (Wiesbaden)

Paul Gans (Mannheim)

Johannes Huinink (Bremen)

Marc Luy (Wien)

Clara H. Mulder (Groningen)

Notburga Ott (Bochum)

Peter Preisendörfer (Mainz)

\section{Board of Reviewers / Gutachterbeirat}

Martin Abraham (Erlangen)

Laura Bernardi (Lausanne)

Hansjörg Bucher (Bonn)

Claudia Diehl (Göttingen)

Andreas Diekmann (Zürich)

Gabriele Doblhammer-Reiter (Rostock)

Henriette Engelhardt-Wölfler (Bamberg)

E.-Jürgen Flöthmann (Bielefeld)

Alexia Fürnkranz-Prskawetz (Wien)

Beat Fux (Zürich)

Joshua Goldstein (Rostock)

Karsten Hank (Köln)

Sonja Haug (Regensburg)

Franz-Josef Kemper (Berlin)

Michaela Kreyenfeld (Rostock)

Aart C. Liefbroer (Den Haag)

Kurt Lüscher (Konstanz)

Dimiter Philipov (Wien)

Tomáš Sobotka (Wien)

Heike Trappe (Rostock) 